\title{
An improved photographic method to estimate the shading effect of obstructions
}

\author{
Aldo Orioli *, Alessandra Di Gangi \\ D.D.E. Dipartimento dell'Energia, Università degli Studi di Palermo, Viale delle Scienze, Edificio 9, 90128 Palermo, Italy
}

Received 4 April 2012; received in revised form 24 July 2012; accepted 25 July 2012

Available online 28 August 2012

Communicated by: Associate Editor J.-L. Scartezzini

\begin{abstract}
A new photographic method is presented to evaluate the shading effects of obstructions on surfaces exposed to the sun. The method overcomes the difficulties caused by the need to accurately describe the surrounding objects to estimate the shading effects by means of the usual tools that use the spatial reconstruction of obstructions or cylindrical or polar suncharts. The photographs of the surrounding objects are used as the background on which the solar disc is depicted at the various hours of the day. In this way it is easily detectable if the sun is visible from the place where the photographs were taken or if the surrounding obstructions obscure the sun.

In spite of the complex mathematical background of the new method, the practical application of the procedure is very simple, and only requires the measurements of three angles for each photograph. The procedure permits to verify the suitability of a generic site for solar exploitation; its main benefit is the simplicity of use and the transparency of the obtained results. This method is particularly useful to evaluate the technical feasibility of small solar systems installed on the buildings of densely urbanised cities.

The accuracy of the method was tested by performing an experimental verification in the field. For this purpose, the sun was photographed at different hours of the day. The photographed solar discs and the calculated sun's positions were compared. The differences between the photographed and calculated sun's positions corresponded to small time lags that do not exceed few minutes in the worst case. To further investigate the reliability of the proposed method, the impact of image distortion, which always affects all methods that use cameras to get information about the photographed reality, was also examined.
\end{abstract}

(C) 2012 Elsevier Ltd. All rights reserved.

Keywords: Shading; Solar access; Solar path; Photovoltaic; Photograph

\section{Introduction}

The amount of solar energy that reaches a surface is affected by several physical parameters such as the latitude, the season, the local climatic conditions, the turbidity of the atmosphere, the tilt and orientation of the receiving surface, and the presence of surrounding surfaces. Buildings in urbanised areas are so densely packed that access to sunlight may be severely restricted. Tall buildings affect

\footnotetext{
* Corresponding author. Tel.: +39 09123861905; fax: +39 091484425.

E-mail addresses: $\quad$ orioli@dream.unipa.it, aldo.orioli@unipa.it (A. Orioli).
}

the distribution of daylight, particularly in winter, and this has important implications for the viability of passive solar buildings. On the other hand, the uncontrolled presence of solar energy may also cause discomfort due to thermal overheating and visual annoyance.

The consequences of shading are particularly important to photovoltaic panels because they are very sensitive to the shading effect. Actually, the output power of photovoltaic panels is dramatically reduced even if a single cell, whose area represents a very small part of the entire surface of the panel, is shadowed. Because the actual performance of solar systems depends on the energy that is absorbed and transformed by solar equipment, a careful evaluation 


\author{
Nomenclature \\ $A S T$ \\ $d \quad$ horizontal distance between the observer and \\ the picture plane $(\mathrm{m})$ \\ ET the equation of time ( $\mathrm{min})$ \\ $H \quad$ hour angle $\left({ }^{\circ}\right)$ \\ $K \quad$ ratio of the distances of points $M^{\prime}$ and $N^{\prime}$ from \\ point $C^{\prime}$ \\ $K_{n} \quad n$th radial coefficient \\ $L \quad$ local latitude $\left(^{\circ}\right)$ \\ LON local longitude $\left(^{\circ}\right)$ \\ LST local standard time (h) \\ $L S M \quad$ local standard time meridian $\left({ }^{\circ}\right)$ \\ $m, n \quad$ coefficients of the plane equation \\ $n_{\text {day }} \quad$ day of year \\ $P_{n} \quad n$th tangential coefficient \\ $P_{1}, P_{2}, P_{3}$ points on the pivoted plane \\ $p, q \quad$ coefficients of the plane equation \\ $r \quad$ radial distance from the image centre $(\mathrm{m})$ \\ $\mathrm{RF}$ \\ image reduction factor
}

$X_{c}, y_{c} \quad$ coordinates of the centre of distortion (m)

$x_{d}, y_{d} \quad$ coordinates of the distorted image point (m)

$x_{\text {sun }}, z_{\text {sun }}$ coordinates of the sun's position in the photograph $(\mathrm{mm})$

$x_{S}, y_{S}, z_{S}$ coordinates of the sun's position on the vertical picture plane $(\mathrm{m})$

$x_{T}, y_{T}, z_{T}$ coordinates of the sun's position on the inclined picture plane $(\mathrm{m})$

$x_{u}, y_{u} \quad$ coordinates of the undistorted image point (m)

$x_{V}, y_{V}, z_{V}$ coordinates of the observer's point (m)

$\beta_{S} \quad$ solar altitude angle $\left(^{\circ}\right)$

$\beta_{M} \quad$ altitude angle of the generic point $M\left(^{\circ}\right)$

$\beta_{N} \quad$ altitude angle of the generic point $N\left({ }^{\circ}\right)$

$\gamma \quad$ inclination angle of the picture plane $\left({ }^{\circ}\right)$

$\delta \quad$ solar declination $\left({ }^{\circ}\right)$

$\varphi \quad$ relative solar azimuth $\left(^{\circ}\right)$

$\varphi_{S} \quad$ solar azimuth $\left(^{\circ}\right)$

$\varphi_{\text {cam }} \quad$ azimuth of the central visual ray line $\left(^{\circ}\right)$ of the energy available is essential to estimate the feasibility of economic investments.

To that end, it is of paramount importance to correctly forecast the direction and the origin of the solar rays and the amount of energy that reaches surfaces. There are many methods that evaluate the direct-normal and diffuse components of solar radiation over an oriented and tilted surface that is located at a specific site (Gueymard, 1987, 2001, 2003a,b; Hay and Davies, 1980; Klucher, 1979; Muneer, 1997; Perez et al., 1986, 1987, 1990; Reindl et al., 1990a,b). These methods were tested at a wide variety of locations and recently have been empirically validated (Loutzenhiser et al., 2007) and improved (Torres et al., 2006, 2008). In the last few years, new methods have been proposed (Chang, 2009; Torres et al., 2010), and a modern approach based on artificial neural networks was also investigated (Chaabene and Ben Ammar, 2008; Lopez et al., 2005; Mellit et al., 2010).

\subsection{Previous investigations}

Generally speaking, the precise assessment of shading caused by surroundings is very difficult because the outside environment is crowded by many natural or artificial objects that have different and complex shapes, such as mountains, trees, buildings, telephone and electric poles, chimneys, billboards, and parabolic antenna.

There are two different approaches to estimate the shading effect due to the objects surrounding a given surface exposed to sunlight. The first approach, which permits to see if the collecting surface results in the shadow or receives daylight, needs the three-dimensional description of each surrounding element by defining its dimensions and position. It was used by Capelluto and Shaviv (2001), Knowles (2003), Levinson et al. (2009), Gomez-Munoz and PortaGandara (2003), Compagnon (2004), Mardaljevic and Rylatt (2003). This approach was also used to evaluate the energy losses of shaded photovoltaic arrays (Quaschning and Hanitsch, 1996; Kovach and Schmid, 1996).

The second approach, which verifies if the direct solar radiation is or not obstructed by an object, requires the measurement of the azimuth and height angles of each vertex of the outline of the surroundings. It employs cylindrical or polar suncharts that describe the sun's paths across the sky during the year. This method, which was initially applied by Quaschning and Hanitsch (1998), was also used by Littefair (1998, 2001, 2002), Robinson and Stone (2004) and Cheung and Chung (2007). In the field of photovoltaic systems, this approach was applied to estimate the irradiance on a partially shaded photovoltaic generator (Drif et al., 2008). The second approach usually requires less data input than the first because the knowledge of all dimensions of the surrounding obstacles is not necessary. Nevertheless, it involves the use of optical instruments such as a compass, a spirit level, a tacheometer or a theodolite, and very precise measurements.

Both approaches have been adopted by numerous software programs that are available today (Awnshade; Ecotect; Leso-Shade; Louver Shading; Overhang Annual Analysis; Overhang Design; Panel Shading; ParaSol; Radiance; Shading II; ShadowFX; Solar Tool; Solar-2; Sombrero 3.01; Suncast; Sundi; Sun_Chart; TRNSYS). 
The shadowing geometry of the surroundings was also recorded by means of photography, either by applying a spherical lens (Grochowski et al., 1997; Woyte, 1997) or by taking several photographs with a customary camera (Caamaño and Lorenzo, 1997. Frei et al., 2000). Skiba et al. (2000) used a digital camera and image processing software and Tomori et al. (2000) proposed taking two or more fisheye photographs to construct a three-dimensional image of the surroundings.

\subsection{Objectives and interest of the new method}

The authors (Cellura et al., 2012) have investigated the possibility of using a photograph as the background on which the sun-disc is represented at various hours by means of calculations based on the geographical data of the site, the orientation of the camera and the date of the day. Such a photographic approach is based on few simple steps and requires the measurements of three angles for each photograph. The first step is to check that the camera, which should be supported by a tripod, is on a horizontal plane. The photograph must be taken by the camera pivoted upwards around the horizontal axis and aimed at the obstructing objects. Because the measurement of the angle of inclination of the camera above the horizontal is needed, the centre of the photograph must correspond to a point of the obstructing objects that is easily recognisable both in the photograph and on the real objects. For example, in Fig. 1 the photograph is aimed at the cornice of the building. The angle of inclination of the camera will be measured aiming a clinometer, or other optical instruments, at the point $C^{\prime}$ of the cornice corresponding to the intersections of the diagonals of the image.
The procedure described by Cellura et al. (2012) has the following weak points:

(1) It is difficult to exactly aim the centre of the photograph at a recognisable point of the obstruction.

(2) The bottom half of photograph is often useless because is occupied by the obstructions, which are not the most significant parts of the picture.

(3) If obstructions are very close to the observer point, the calculated sun's positions may be not included in the photograph because are situated above the upper edge of the picture.

When the solar path is low, which usually happens during winter, it is more likely that the centre of the photograph intersects a point of the obstruction. Adversely, when the solar path is high, in order to photograph an adequate portion of the sky it is necessary to pivot the camera upward. In this case, the centre of photograph may not be detectable and measurable because, as it is depicted in Fig. 2, it is impossible to recognise an indefinite point $C^{\prime}$ in the sky.

In order to get the angle of inclination of the camera, the photograph should be taken through the lenses of a tacheometer. Because the main purpose of the proposed method is using simple photographic tools, the procedure has been modified in order to reduce the weak points of the method of Cellura et al. (2012) and use photographs that are taken without the need of following too much strict rules. The improved procedure only needs that a small area of the obstruction is photographed and, instead of measuring of the centre of the photograph it requires the selection of two points freely chosen on the middle vertical axis of the picture.

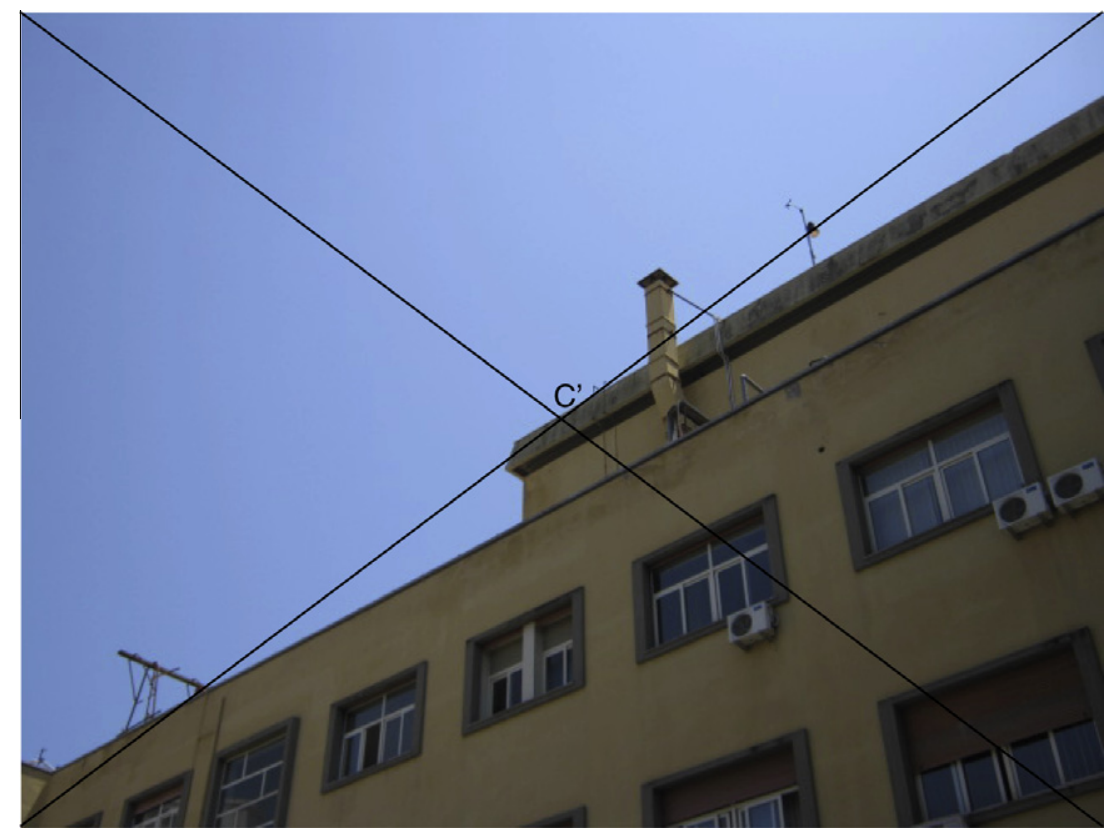

Fig. 1. Photograph aimed to a point of the obstruction. 


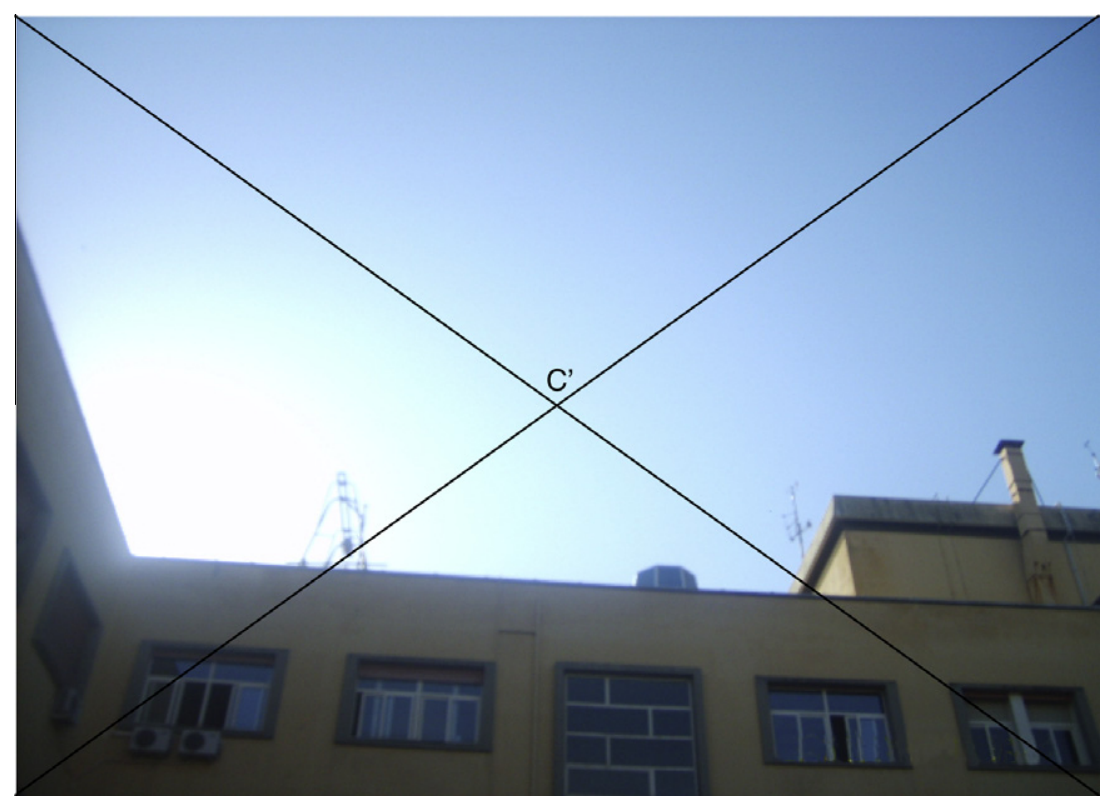

Fig. 2. Photograph aimed to a point of the sky.

\section{The improved photographic approach to the evaluation of the shading effect}

It is known that a photograph obeys the rules of the linear perspective projection. Such a geometric transformation allows for the three-dimensional representation of objects as they are seen by an observer in reality. Photogrammetry systems usually employ the properties of perspective to survey lands. Some methods have been developed to obtain metric data of objects, such as facades, windows or apertures (Ordonez et al., 2008), and 3D reconstructions of buildings from photographic images (Van den Heuvel, 1998). The perspective view of an object is obtained by the intersections on a virtual picture plane of the rays emerging from the object and converging towards the observer's eye. The virtual picture plane is like the glass of a window on which the shape of the object is traced by the viewer. A photograph taken with a camera inclined by an angle $\gamma$ above the horizontal corresponds to a perspective view depicted on a virtual plane pivoted by $\gamma$ around the horizon line. The sun's position, which is indicated by the point $T$ in Fig. 3, can be calculated as the intersection of the solar ray with the inclined picture plane.

With reference to the three-dimensional orthogonal coordinate system shown in Fig. 3, which places the origin on the horizon line, the position of point $T$ referred to the inclined picture plane can be evaluated with the following expressions (Cellura et al., 2012), whose derivation is shown in Appendix A:

$$
\begin{gathered}
\overline{O T^{\prime \prime}}=\frac{d \tan \left(\beta_{S}\right) \tan (\gamma)}{\tan \left(\beta_{S}\right) \tan (\gamma)+\cos (\varphi)} \\
\overline{T T^{\prime \prime}}=\frac{d \sin (\varphi)}{\left[\tan \left(\beta_{S}\right) \tan (\gamma)+\cos (\varphi)\right] \cos (\gamma)}
\end{gathered}
$$

in which $d$ is the distance between the observer and the picture plane, $\beta_{S}$ is the solar altitude and $\varphi$ is the relative solar azimuth, i.e. the difference between the solar azimuth $\varphi_{S}$ and the azimuth of the central visual ray line. As it is shown in Appendix A, solar altitude $\beta_{S}$ and solar azimuth $\varphi_{S}$ can be calculated by means of the ASHRAE relations (ASHRAE Handbook - Fundamentals, 2009) using the equations of Carruthers (1990) to evaluate the solar declination and the equation of time. The direction of the central visual ray line, which corresponds to the direction in which the camera is pointing, is defined by the azimuth angle $\varphi_{\text {cam }}$.

Angle $\gamma$, which indicates the inclination of the camera above the horizontal, can be determined by means of a couple of generic point $M^{\prime}$ and $N^{\prime}$ located on the vertical line containing point $C^{\prime}$ as it is depicted in Fig. 4.

With reference to Fig. 5, which is a simplified side view of Fig. 4, the following relations are valid for right triangles $O^{\prime} C^{\prime}, V, M^{\prime}, C^{\prime}, V$ and $N^{\prime}, C^{\prime}, V$, respectively:

$$
\begin{aligned}
\overline{C^{\prime} V} & =\overline{O^{\prime} V} \cos (\gamma) \\
\overline{M^{\prime} V} & =\frac{\overline{C^{\prime} V}}{\cos \left(\gamma-\beta_{M}\right)} \quad \overline{M^{\prime} C^{\prime}}=\overline{M^{\prime} V} \sin \left(\gamma-\beta_{M}\right) \\
& =\overline{O^{\prime} V} \cos (\gamma) \tan \left(\gamma-\beta_{M}\right) \\
\overline{N^{\prime} V} & =\frac{\overline{C^{\prime} V}}{\cos \left(\gamma-\beta_{N}\right)} \quad \overline{N^{\prime} C^{\prime}}=\overline{N^{\prime} V} \sin \left(\gamma-\beta_{N}\right) \\
& =\overline{O^{\prime} V} \cos (\gamma) \tan \left(\gamma-\beta_{N}\right)
\end{aligned}
$$

Eqs. (3) and (4) can be rearranged in the following form:

$$
K=\frac{\overline{M^{\prime} C^{\prime}}}{\overline{N^{\prime} C^{\prime}}}=\frac{\tan \left(\gamma-\beta_{M}\right)}{\tan \left(\gamma-\beta_{N}\right)}=\frac{\frac{\tan (\gamma)-\tan \left(\beta_{M}\right)}{1+\tan (\gamma) \tan \left(\beta_{M}\right)}}{\frac{\tan (\gamma)-\tan \left(\beta_{N}\right)}{1+\tan (\gamma) \tan \left(\beta_{N}\right)}}
$$




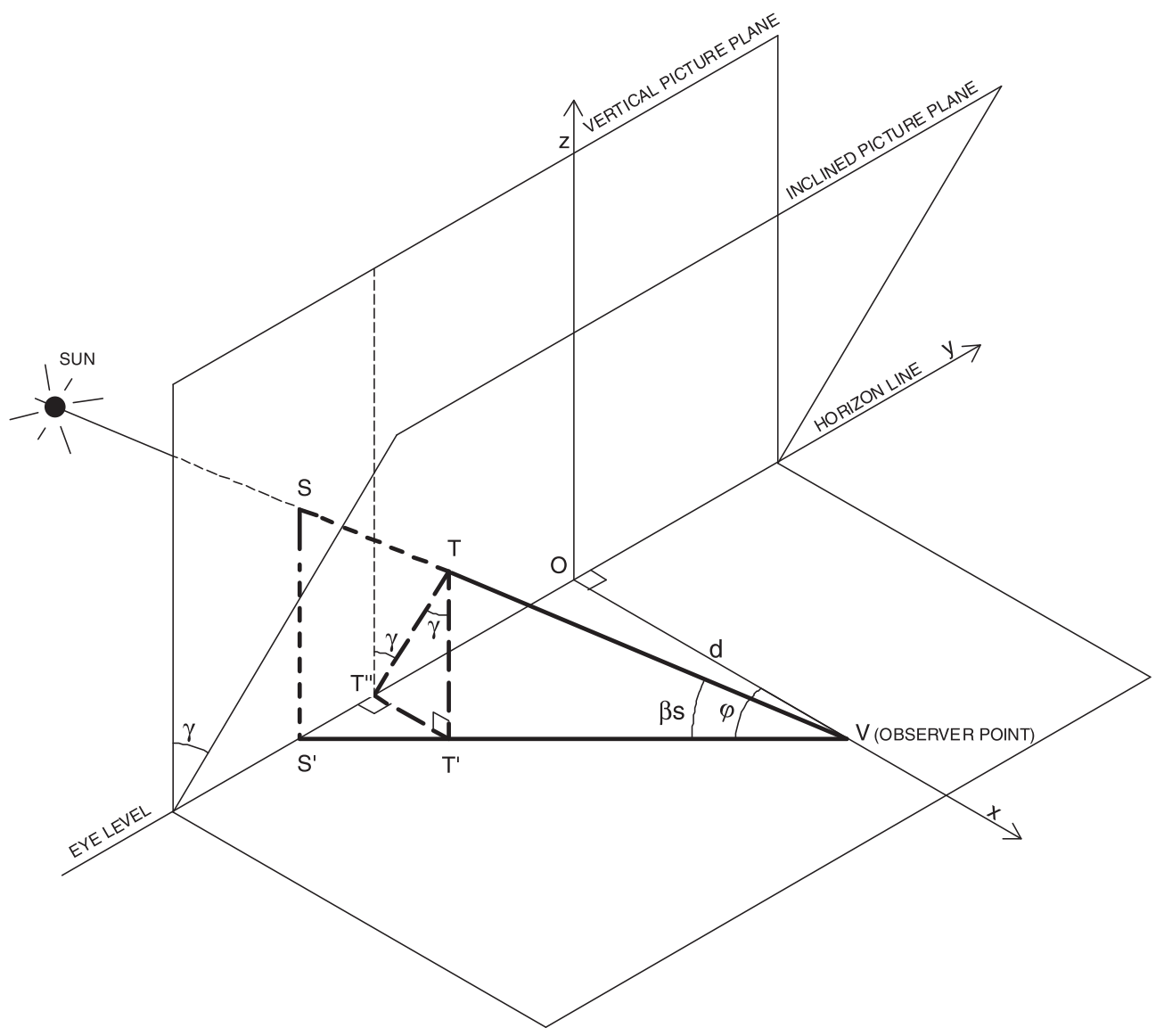

Fig. 3. Sketch of the sun's position on an inclined picture plane.

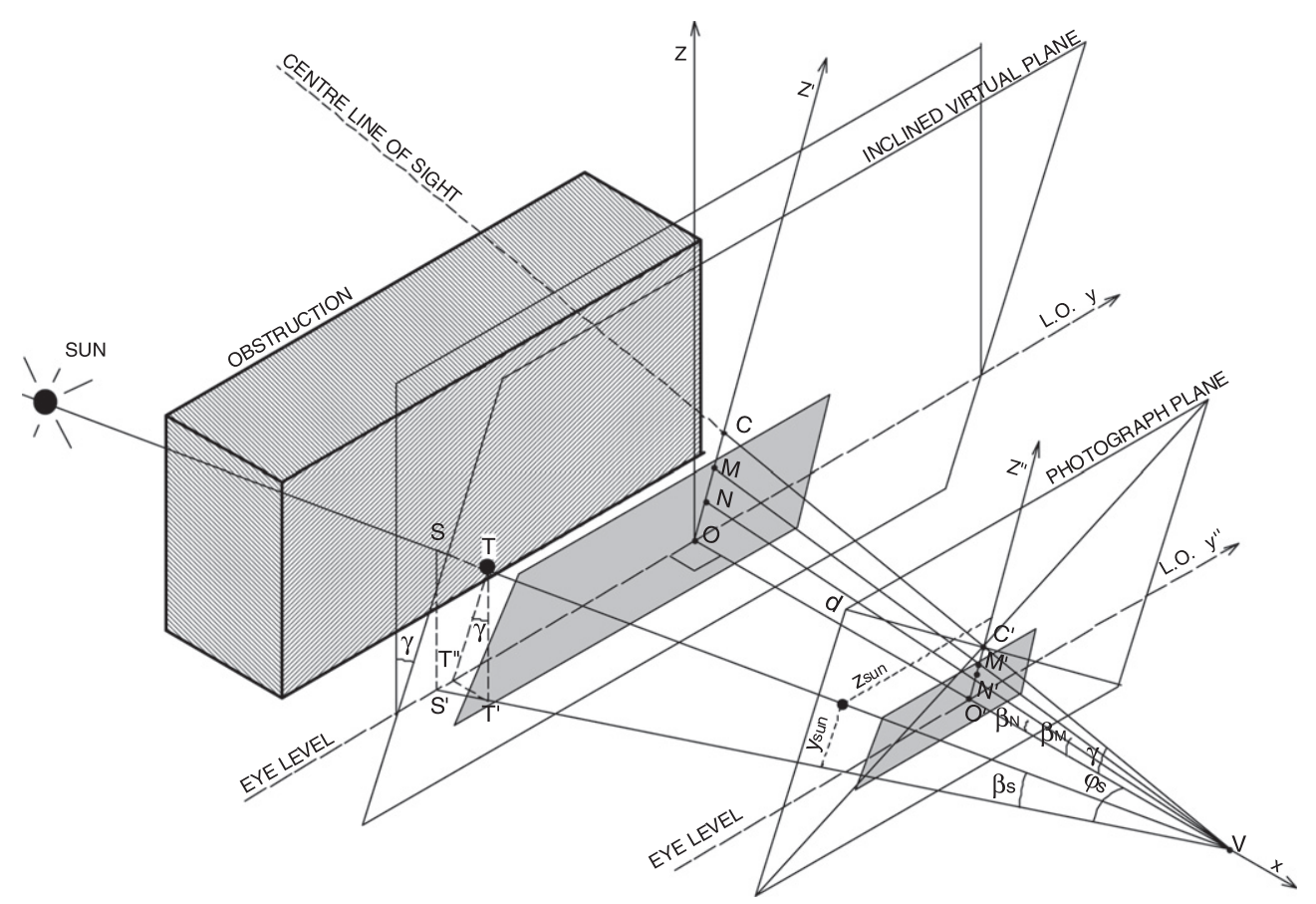

Fig. 4. Sketch of the perspective representation on an inclined picture plane. 


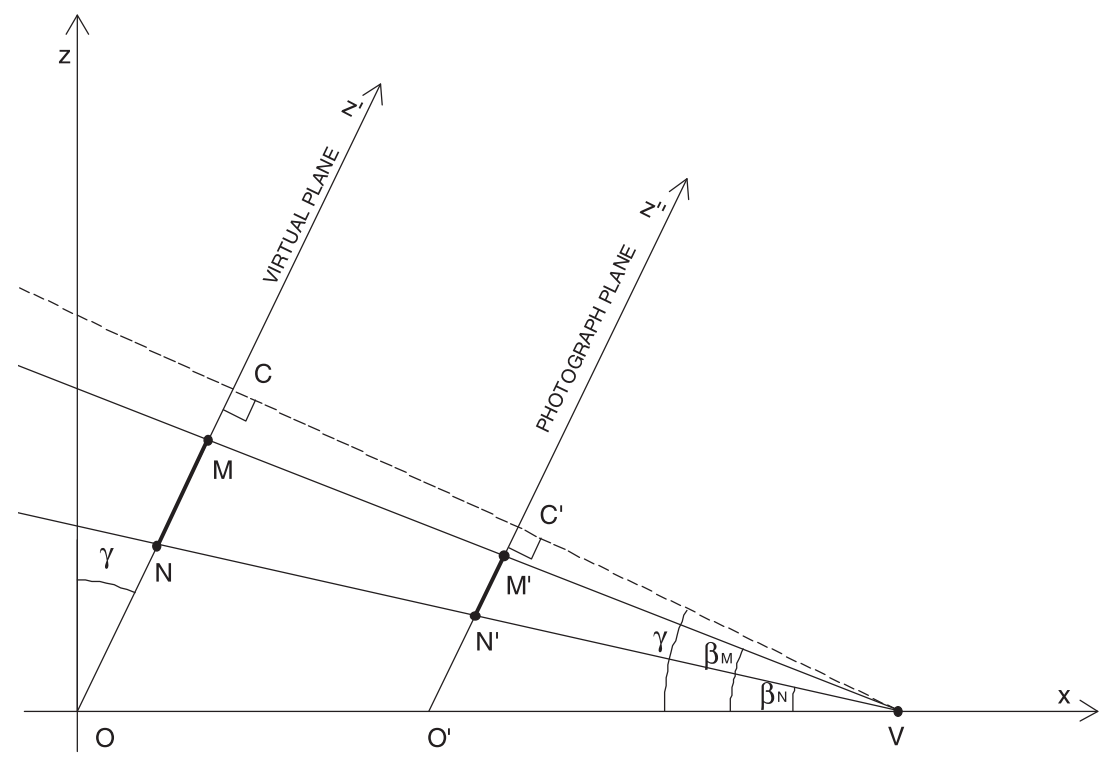

Fig. 5. Side view of Fig. 4.

where $K$ represents the ratio of the distances of points $M^{\prime}$ and $N^{\prime}$ from point $C^{\prime}$. Eq. (5) is equivalent to the following quadratic equation:

$$
\begin{aligned}
& {\left[\tan \left(\beta_{N}\right)-K \tan \left(\beta_{M}\right)\right] \tan ^{2}(\gamma)+(1-K)\left[1-\tan \left(\beta_{M}\right)\right.} \\
& \left.\quad \times \tan \left(\beta_{N}\right)\right] \tan (\gamma)+K \tan \left(\beta_{N}\right)-\tan \left(\beta_{M}\right)=0
\end{aligned}
$$

from which $\tan (\gamma)$ can be extracted to evaluate angle $\gamma$. The distances $\overline{M^{\prime} C^{\prime}}$ and $\overline{N^{\prime} C^{\prime}}$ from the centre point $C^{\prime}$ can be easily measured in the photograph; angles $\beta_{M}$ and $\beta_{N}$, which are the altitude angle of point $M$ and $N$ on the virtual plane, have to be measured aiming the clinometer to the points of the real obstructing objects corresponding to points $M^{\prime}$ and $N^{\prime}$ of the photograph. Because centre $C^{\prime}$ can be higher than the tallest part of the obstructing objects, a widest portion of sky can be represented in the photograph.

In Eq. (1) $d$ is the horizontal distance between the observer point and the intersection of the horizon line with the

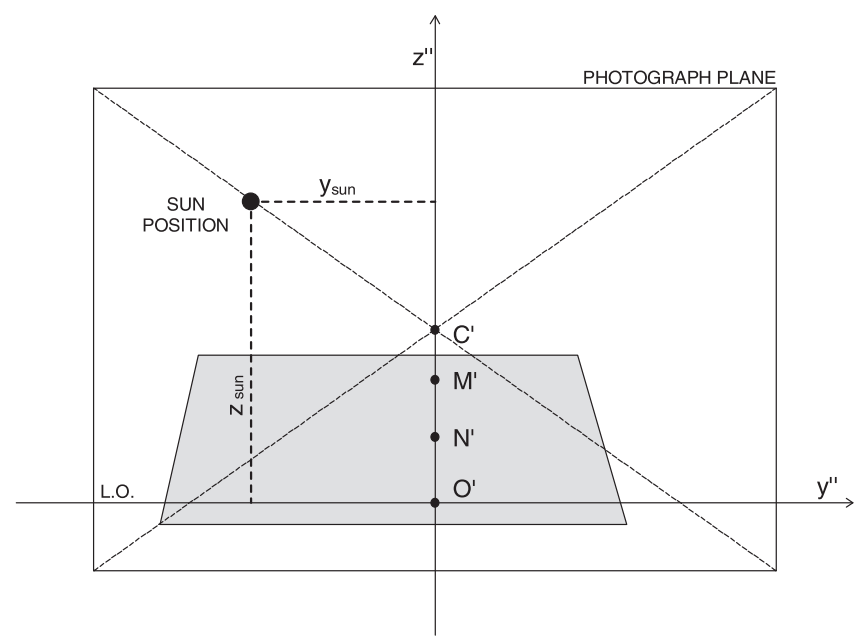

Fig. 6. Sun's position identification in the photograph. picture plane. If this distance is varied, the width of the picture plane and the dimensions of the objects in the photograph are modified. The original proportions of the objects do not vary because only the magnification of the image changes. Considering that $d$ only represents a virtual distance, ascertaining its value may appear difficult. Fortunately, $d$ is not needed because it is only necessary to know the image magnification or the reduction, and this can be achieved without measuring distance $d$.

The sun's position on the photograph can be represented using coordinates $y_{\text {sun }}$ and $z_{\text {sun }}$ shown in Fig. 6 using the following equations derived by Cellura et al. (2012):

$$
\begin{gathered}
y_{\text {sun }}=\frac{\tan \left(\beta_{N}\right) \tan (\gamma)}{\tan \left(\beta_{N}\right) \tan (\gamma)+\cos (\varphi)} \cdot \frac{\overline{C^{\prime} N^{\prime}}}{D} \\
z_{\text {sun }}=\frac{\sin (\varphi)}{\left[\tan \left(\beta_{N}\right) \tan (\gamma)+\cos (\varphi)\right] \cos (\gamma)} \cdot \frac{\overline{C^{\prime} N^{\prime}}}{D}
\end{gathered}
$$

where:

$$
\begin{gathered}
D=\sqrt{D_{x}^{2}+D_{z}^{2}} \\
D_{x}=\frac{\tan ^{2}(\gamma)}{\tan ^{2}(\gamma)+1}-\frac{\tan \left(\beta_{N}\right) \tan (\gamma)}{\tan \left(\beta_{N}\right) \tan (\gamma)+1} \\
D_{z}=\frac{\tan (\gamma)}{\tan ^{2}(\gamma)+1}-\frac{\tan \left(\beta_{N}\right)}{\tan \left(\beta_{N}\right) \tan (\gamma)+1}
\end{gathered}
$$

Quantity $\overline{C^{\prime} N^{\prime}}$ represents the distance from the centre of the photograph, i.e. the intersection of diagonals, to a generic point $N^{\prime}$ located on the vertical line that contains point $C^{\prime}$. If $\overline{C^{\prime} N^{\prime}}$ is measured in centimetres, coordinates $y_{\text {sun }}$ and $z_{\text {sun }}$ in Eq. (7) are expressed in centimetres and are independent from the value of the virtual distance $d$. Coordinate $z_{\text {sun }}$ refers to the $y$-axis that corresponds to the horizon line of the perspective view whose distance from the centre of the photograph is given by:

$\overline{C^{\prime} O^{\prime}}=\sqrt{\left(\frac{\tan ^{2}(\gamma)}{\tan ^{2}(\gamma)+1}\right)^{2}+\left(\frac{\tan (\gamma)}{\tan ^{2}(\gamma)+1}\right)^{2}} \cdot \frac{\overline{C^{\prime} N^{\prime}}}{D}$ 


\section{Application of the new photographic method and analysis of the results}

The practical application of the new method is very simple and only requires the measurements of angles $\beta_{M}, \beta_{N}$, which are the zenith angles of two points chosen in the vertical axis of the photograph, and $\varphi_{c a m}$, which is the azimuth angle of the camera, for each photograph. The first step is to check that the camera is on a horizontal plane. This step, which can be done with a simple spirit level, is important because the horizon line in the photograph must be horizontal as in the actual perspective view; to keep the camera still in the right position, it would be better to use a tripod. Because the measurements of angles $\beta_{M}$ and $\beta_{N}$ are needed, the vertical axis of the photograph should contain points of the obstructing objects that are easily recognisable both in the photograph and on the real objects. For example, if the obstructing objects are the surrounding buildings, then the photograph should be aimed at windows, balconies, ledges or other common elements of the building's facade.

Once the photograph is taken, angles $\beta_{M}, \beta_{N}$ and $\varphi_{c a m}$ must be measured and recorded. Angle $\varphi_{\text {cam }}$, which represents the camera's orientation to the south, can be measured with a compass. Otherwise, it can be more exactly found on an oriented map of the installation site. Because the perspective of an inclined picture plan is sensitive to the inclination angle, altitude angles $\beta_{M}$ and $\beta_{N}$ should be measured with accurate optical instruments, such as a tacheometer or a theodolite. Actually, because term $D$ is related to $\beta_{N}$ and $\gamma$, which in turn also depends on $\beta_{M}$, the inaccurate measurement of these angles affects the precise scaling down required by the method. Nevertheless, it was observed that if the azimuth and altitude angles are measured with a degree of accuracy of $\pm 0.5^{\circ}$, the method will yield sufficiently reliable results with a few minutes of difference; for this reason a simple clinometer can be also used.

Once the angular data are recorded, the field work is over and calculations can be performed. Using the distance $\overline{C^{\prime} M^{\prime}}$ and $\overline{C^{\prime} N^{\prime}}$ measured in the photograph, angle $\gamma$ can be evaluated solving Eq. (6). Then, by means of Eq. (9), the position of the origin $O^{\prime}$ in the photograph can be defined in order to draw the horizontal axis of the orthogonal coordinate system. Finally, the sun's position can be evaluated with Eq. (7) using the values of solar azimuth $\varphi_{S}$ and altitude $\beta_{S}$.

\subsection{Results}

The procedure described above was used to draw the sun's positions on photographs of the building of the Dipartimento dell'Energia taken in different days of the year with an ordinary camera with a focal length of $50 \mathrm{~mm}$. Using the data listed in Table 1, the sun's angular and rectangular coordinates at different hours were computed with a simple routine using VBA (Visual Basic)
Table 1

Data for calculating the sun's positions of Fig. 7.

\begin{tabular}{llll}
\hline Location data & Photograph data & \\
\hline Date & 07 October 2011 & Original size $(\mathrm{cm})$ & $18.1 \times 13.6$ \\
City & Palermo & Camera azimuth $\varphi_{\text {cam }}$ & $-19.90^{\circ}$ \\
Longitude & $13^{\circ} 21^{\prime} 0^{\prime \prime} \mathrm{E}$ & Point $M^{\prime}$ altitude $\beta_{M}$ & $36.70^{\circ}$ \\
Latitude & $38^{\circ} 7^{\prime} 0^{\prime \prime} \mathrm{N}$ & Point $N^{\prime}$ altitude $\beta_{N}$ & $28.00^{\circ}$ \\
$L S M$ & +1 & $\overline{C^{\prime} M^{\prime}}(\mathrm{cm})$ & 2.05 \\
& & $\overline{C^{\prime} N^{\prime}}(\mathrm{cm})$ & 5.15 \\
\hline
\end{tabular}

Table 2

Calculated coordinates of sun's positions of Fig. 7.

\begin{tabular}{lllll}
\hline Time $(\mathrm{h})$ & Azimuth $\varphi_{S}\left({ }^{\circ}\right)$ & Altitude $\beta_{S}\left(^{\circ}\right)$ & $y_{\text {sun }}(\mathrm{mm})$ & $z_{\text {sun }}(\mathrm{mm})$ \\
\hline $09: 15$ & -49.50 & 32.96 & -9.03 & 16.11 \\
$09: 30$ & -45.85 & 35.14 & -7.58 & 16.58 \\
$09: 45$ & -41.98 & 37.19 & -6.20 & 17.01 \\
$10: 00$ & -37.88 & 39.08 & -4.87 & 17.42 \\
$10: 15$ & -33.56 & 40.81 & -3.58 & 17.81 \\
$10: 30$ & -29.01 & 42.34 & -2.32 & 18.18 \\
$10: 45$ & -24.23 & 43.66 & -1.08 & 18.54 \\
$11: 00$ & -19.25 & 44.75 & 0.16 & 18.89 \\
$11: 15$ & -14.09 & 45.60 & 1.40 & 19.23 \\
$11: 30$ & -8.79 & 46.19 & 2.66 & 19.57 \\
$11: 45$ & -3.40 & 46.50 & 3.95 & 19.91 \\
$12: 00$ & 2.02 & 46.54 & 5.27 & 20.25 \\
$12: 15$ & 7.43 & 46.29 & 6.65 & 20.59 \\
$12: 30$ & 12.76 & 45.78 & 8.09 & 20.94 \\
\hline
\end{tabular}

macros in Microsoft Excel. Table 2 lists the results of calculations.

In Fig. 7 the calculated sun's positions are represented by the shapes of small doughnuts. The values of $z_{\text {sun }}$ listed in Table 2 refer to the horizon line that resulted to be set $18.16 \mathrm{~cm}$ above the centre of the photograph. Obviously the values of the calculated coordinates of sun's positions, which refer to the original size of the photograph, do not correspond to the values reported in Fig. 7 because the dimensions of the photograph were modified to follow the editor's artwork instructions.

As it is shown in Fig. 7, the observer cannot see the sun before 9:30, and consequently the collecting surface will be shaded. Starting from few minutes after 9:45-10:00, the building again will obscure the sun. Table 3 lists the input data for the calculations performed for another photograph of the building of the D.D.E.

The small doughnuts that represent the sun's positions in Fig. 8 were drawn by using the results of calculations listed in Table 4; the horizon line was set $16.32 \mathrm{~cm}$ above the centre of the photograph. The building shadows the observer until 11.15.

\subsection{Experimental verification}

The accuracy of the proposed method was also tested by performing some experimental verification in the field. For this purpose, the sun was photographed by a camera at different hours of the day; the camera was fixed on a tripod to 


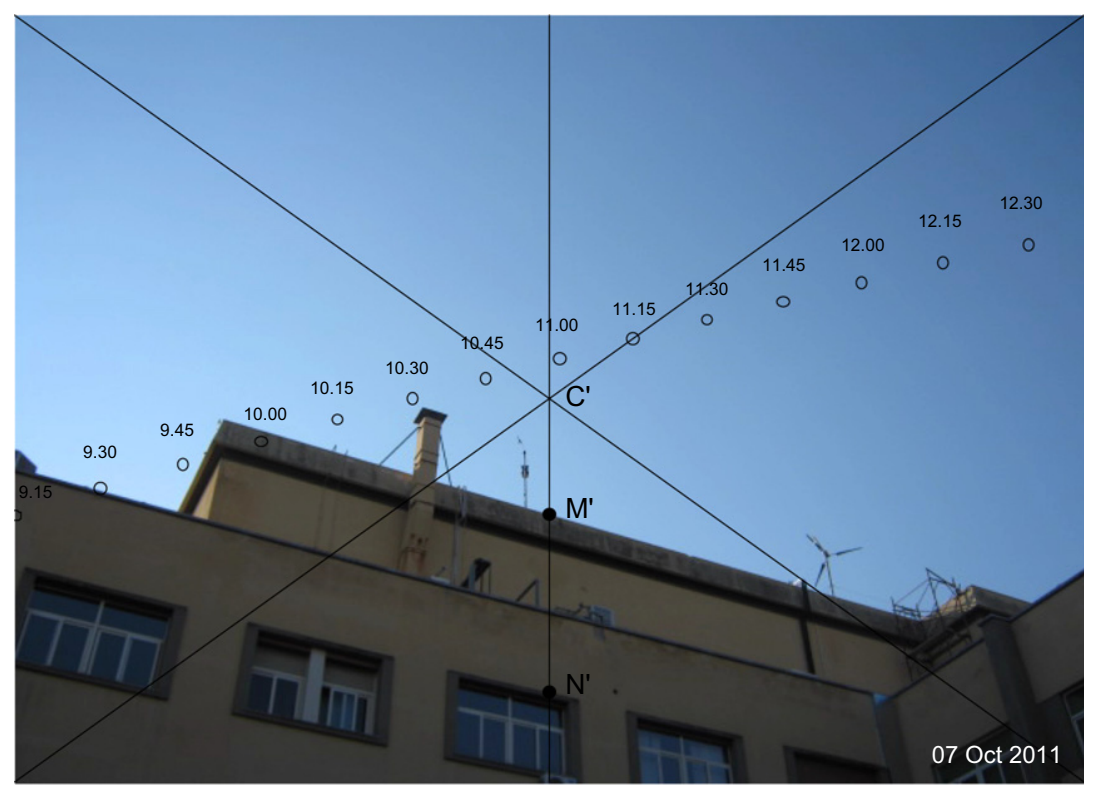

Fig. 7. Calculated sun's positions in a photograph on 7 October 2011.

Table 3

Data for calculating the sun's positions of Fig. 8.

\begin{tabular}{llll}
\hline Location data & Photograph data \\
\hline Date & 12 October 2011 & Original size $(\mathrm{cm})$ & $18.1 \times 13.6$ \\
City & Palermo & Camera azimuth $\varphi_{c a m}$ & $9.00^{\circ}$ \\
Longitude & $13^{\circ} 21^{\prime} 0^{\prime \prime} \mathrm{E}$ & Point $M^{\prime}$ altitude $\beta_{M}$ & $33.70^{\circ}$ \\
Latitude & $38^{\circ} 7^{\prime} 0^{\prime \prime} \mathrm{N}$ & Point $N^{\prime}$ altitude $\beta_{N}$ & $26.70^{\circ}$ \\
$L S M$ & +1 & $\overline{C^{\prime} M^{\prime}}(\mathrm{cm})$ & 2.15 \\
& & $\overline{C^{\prime} N^{\prime}}(\mathrm{cm})$ & 4.60 \\
\hline
\end{tabular}

keep the view still. With the aim of taking distinct photographs of the solar disc, the camera's lenses were protected by dark glass. The shots of the solar disc at the various hours were overlapped in the photographs of Figs. 7 and 8 to obtain the image of Figs. 9 and 10.

It is easy to verify the accuracy of the method proposed by comparing the photographed and the calculated sun positions in Figs. 9 and 10. Some small differences can be observed for the sun's positions that are distant from the vertical axis of the photograph. Tables 5 and 6 list the absolute percentage differences between the photographed and calculated coordinates of sun's positions on 7 and 12 October 2011.

The position differences observed in Figs. 9 and 10 may be due to the impossibility of keeping the camera perfectly horizontal while photographing the building and the solar

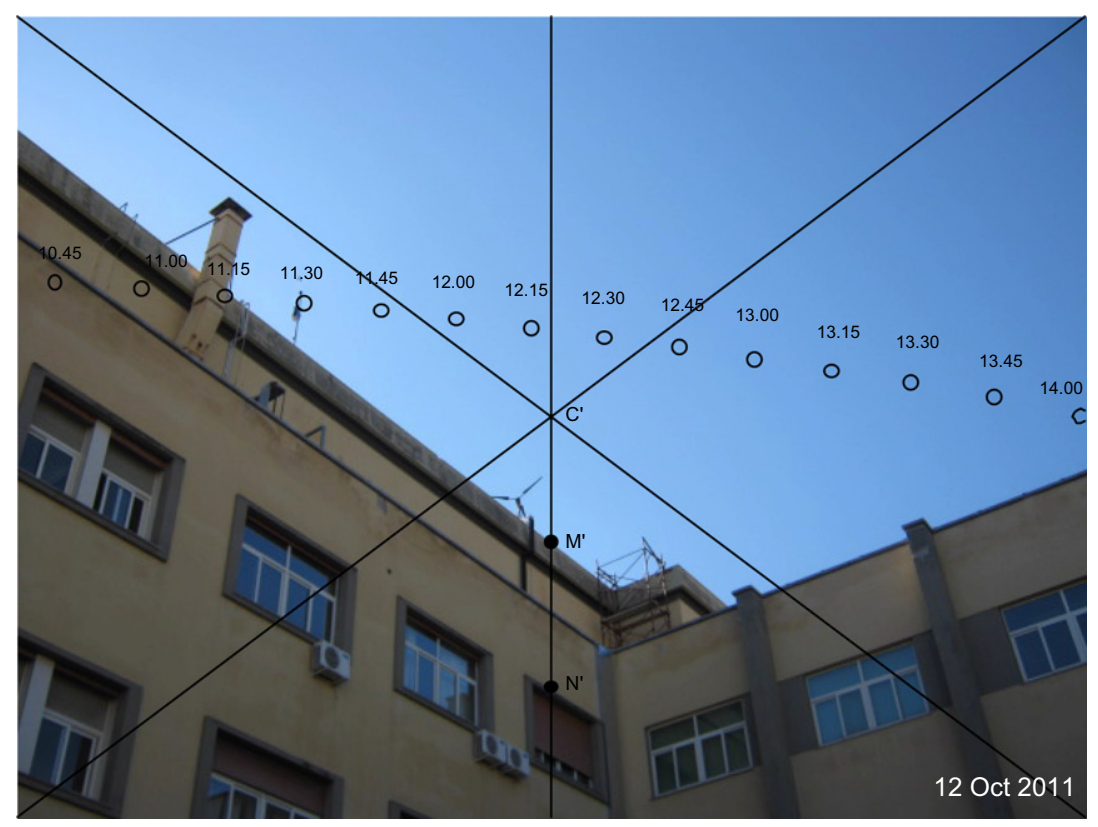

Fig. 8. Calculated sun's positions in a photograph on 12 October 2011. 
Table 4

Calculated coordinates of sun's positions of Fig. 8.

\begin{tabular}{lclll}
\hline Time $(\mathrm{h})$ & Azimuth $\varphi_{S}\left(^{\circ}\right)$ & Altitude $\beta_{S}\left(^{\circ}\right)$ & $y_{\text {sun }}(\mathrm{mm})$ & $z_{\text {sun }}(\mathrm{mm})$ \\
\hline $10: 45$ & -22.98 & 41.97 & -8.39 & 18.59 \\
$11: 00$ & -18.13 & 43.00 & -6.92 & 18.48 \\
$11: 15$ & -13.13 & 43.80 & -5.52 & 18.36 \\
$11: 30$ & -8.01 & 44.34 & -4.18 & 18.23 \\
$11: 45$ & -2.81 & 44.62 & -2.87 & 18.10 \\
$12: 00$ & 2.42 & 44.63 & -1.60 & 17.96 \\
$12: 15$ & 7.62 & 44.37 & -0.33 & 17.81 \\
$12: 30$ & 12.76 & 43.85 & 0.92 & 17.65 \\
$12: 45$ & 17.77 & 43.07 & 2.18 & 17.48 \\
$13: 00$ & 22.63 & 42.05 & 3.46 & 17.29 \\
$13: 15$ & 27.30 & 40.81 & 4.76 & 17.09 \\
$13: 30$ & 31.78 & 39.35 & 6.10 & 16.88 \\
$13: 45$ & 36.04 & 37.71 & 7.50 & 16.64 \\
$14: 00$ & 40.10 & 35.89 & 8.96 & 16.38 \\
\hline
\end{tabular}

disc; in effect the photograph of Fig. 9 seems to be slightly counterclockwise rotated. Moreover, the effect of the photograph distortion may be also relevant to the issue, as it is shown in the next paragraph.

\subsection{Influence of photograph distortion}

It is well known that lenses do not form perfect images (Jenkins and White, 1976). Aberrations, which inevitably affect each photographic image, may cause the observed differences between the calculated and photographed sun's positions. Actually due to the aberrations introduced by the lenses the image is only an imperfect replica of the photographed object. Aberrations are departures of the performance of an optical system from the predictions of geometric optics based on the paraxial approximation. As it is shown in Fig. 11, an ideal lens is characterised by some important optical properties, based on the Gaussian theory:

(1) All rays parallel to the optical axis of the system are refracted in the focal point $F_{2}$, which is located at a distance $f$ from the lens.

(2) All rays passing by the middle point of the lens are not refracted.

(3) All rays passing by the focal point $F_{1}$ are refracted parallel to the optical axis of the system.

(4) The image of an object located at a distance $2 f$ from the lens is focalized at a distance $2 f$ from the lens and has the same dimensions of the object $\left(\overline{A O}=\overline{A_{1} O_{1}}\right)$.

(5) The thickness of the lens and the wavelength of the light do not affect the above properties.

Actually, the Gaussian theory is only valid when the light is monochromatic, the lens is very thin and the angles made by all rays with the optical axis of the system are infinitely small, i.e. the rays are paraxial. In practice the paraxial condition is fairly approximated if the angle made by the ray with the optical axis is less than five degrees; for angles greater than five degrees the light emerging from a point of the object after transmission through the optical system does not converge into a single point and the images projected are generally blurred and badly defined. Fig. 12 shows the optical behaviour of a real converging lens: different rays emerging from point $\mathrm{A}$ do not converge in the same point. Moreover, depending on each projected ray, the images at a distance $2 f$ from the lens have different dimensions $\left(\overline{A O} \neq \overline{A_{1} O_{1}} \neq \overline{A_{2} O_{1}} \neq \overline{A_{3} O_{1}}\right)$.

Aberrations can be monochromatic and chromatic. Monochromatic aberrations, which are due to the geometry

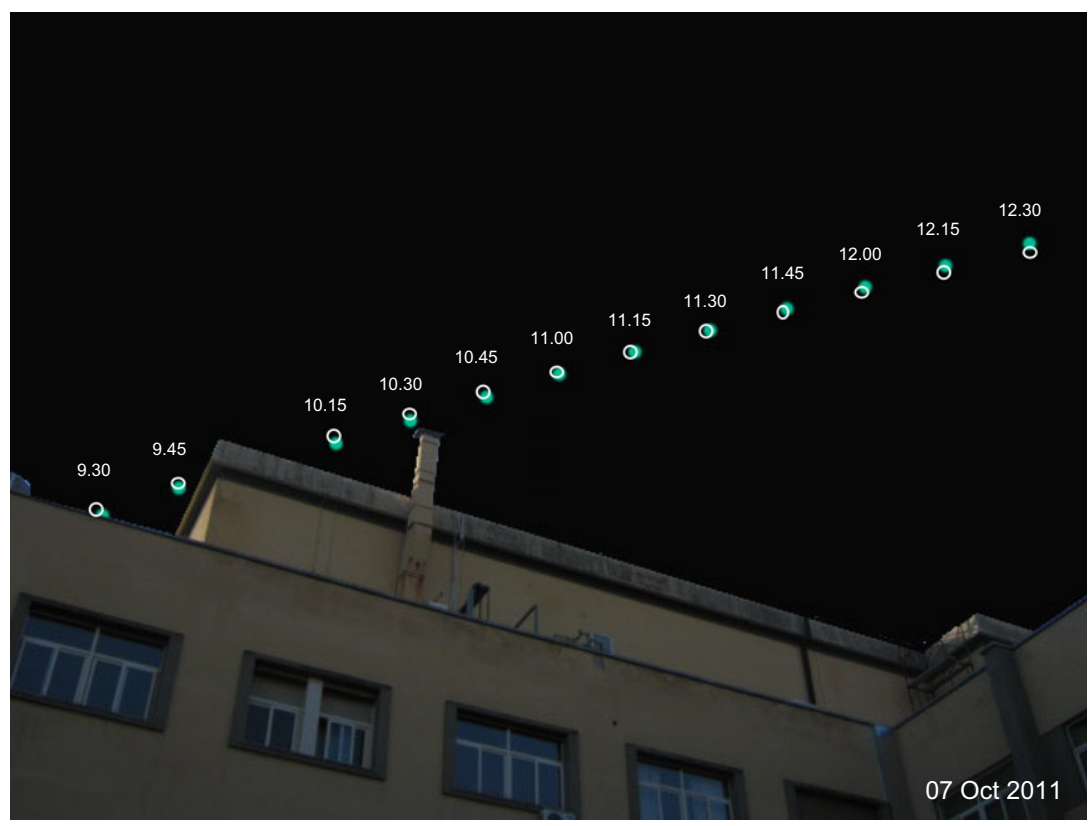

Fig. 9. Comparison between calculated and photographed sun positions on 7 October 2011. 


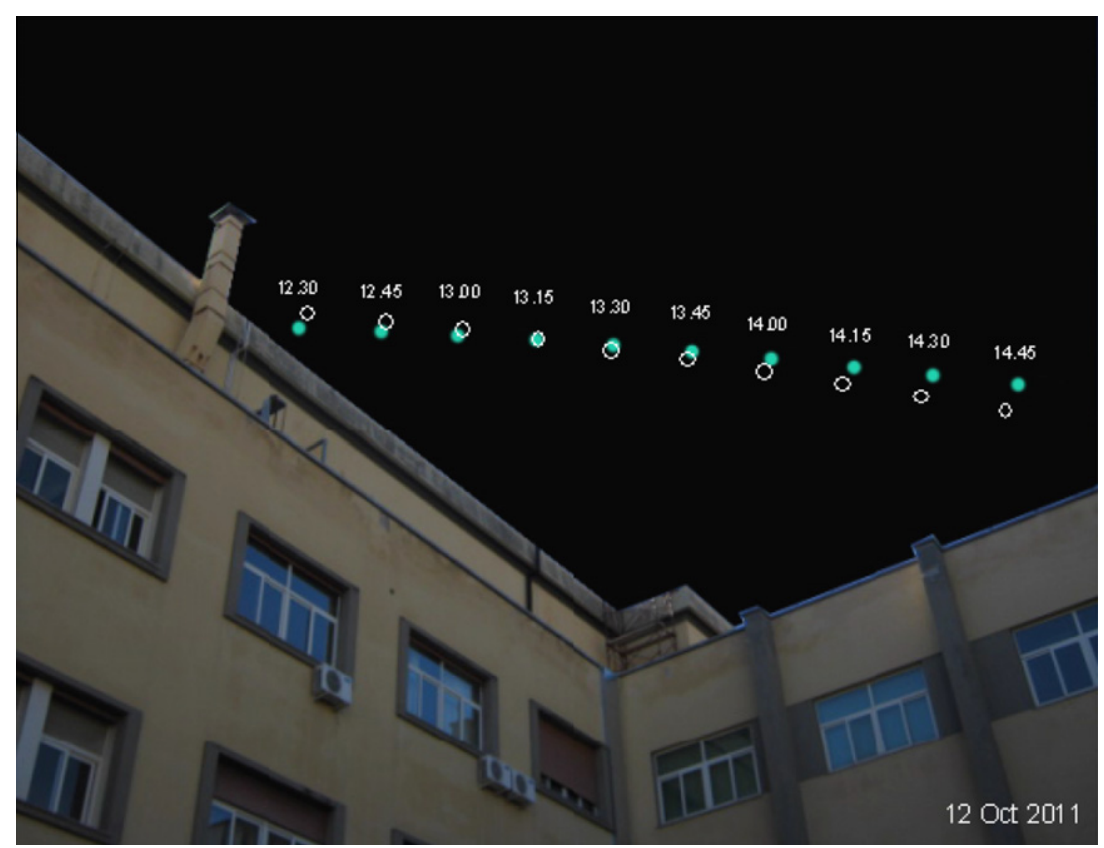

Fig. 10. Comparison between calculated and photographed sun positions on 12 October 2011.

Table 5

Absolute percentage differences between photographed and calculated coordinates of sun's positions of Fig 9.

\begin{tabular}{|c|c|c|c|c|c|c|}
\hline \multirow[t]{2}{*}{ Time (h) } & \multicolumn{3}{|c|}{ Horizontal position $y_{\text {sun }}$} & \multicolumn{3}{|c|}{ Vertical position, $z_{\text {sun }}$} \\
\hline & Photogr. (cm) & Calcul. (cm) & Abs. diff. ( $\%)$ & Photogr. (cm) & Calcul. $(\mathrm{cm})$ & Abs. diff. $(\%)$ \\
\hline 09:30 & -7.50 & -7.58 & 1.07 & 16.52 & 16.58 & 0.36 \\
\hline 09:45 & -6.20 & -6.20 & 0.00 & 16.99 & 17.01 & 0.12 \\
\hline 10:00 & -3.58 & -3.58 & - & 17.71 & 17.81 & - \\
\hline $10: 15$ & -2.32 & -2.32 & 0.00 & 18.08 & 18.18 & 0.56 \\
\hline 10:30 & -1.05 & -1.08 & 0.00 & 18.49 & 18.54 & 0.55 \\
\hline 10:45 & 0.16 & 0.16 & 2.86 & 18.87 & 18.89 & 0.27 \\
\hline 11:00 & 1.42 & 1.40 & 0.00 & 19.23 & 19.23 & 0.11 \\
\hline $11: 15$ & 2.68 & 2.66 & 1.41 & 19.61 & 19.57 & 0.00 \\
\hline 11:30 & 3.97 & 3.95 & 0.75 & 19.98 & 19.91 & 0.20 \\
\hline 11:45 & 5.28 & 5.27 & 0.50 & 20.32 & 20.25 & 0.35 \\
\hline 12:00 & 6.63 & 6.65 & 0.19 & 20.70 & 20.59 & 0.34 \\
\hline $12: 15$ & 8.03 & 8.09 & 0.30 & 21.05 & 20.94 & 0.53 \\
\hline $12: 30$ & -7.50 & -7.58 & 0.75 & 16.52 & 16.58 & 0.52 \\
\hline Mean absolute diff. & 0.65 & Mean absolute diff. & 0.33 & & & \\
\hline
\end{tabular}

Table 6

Absolute percentage differences between photographed and calculated coordinates of sun's positions of Fig 10.

\begin{tabular}{|c|c|c|c|c|c|c|}
\hline \multirow[t]{2}{*}{ Time (h) } & \multicolumn{3}{|c|}{ Horizontal position $y_{\text {sun }}$} & \multicolumn{3}{|c|}{ Vertical position, $z_{\text {sun }}$} \\
\hline & Photogr. (cm) & Calcul. $(\mathrm{cm})$ & Abs. diff. $(\%)$ & Photogr. (cm) & Calcul. (cm) & Abs. diff. $(\%)$ \\
\hline $12: 30$ & -4.29 & -4.18 & 2.56 & 18.00 & 18.23 & 1.28 \\
\hline $12: 45$ & -2.92 & -2.87 & 1.71 & 17.94 & 18.10 & 0.89 \\
\hline $13: 00$ & -1.67 & -1.60 & 4.19 & 17.89 & 17.96 & 0.39 \\
\hline $13: 15$ & -0.36 & -0.33 & 8.33 & 17.82 & 17.81 & 0.06 \\
\hline $13: 30$ & 0.94 & 0.92 & 2.13 & 17.72 & 17.65 & 0.40 \\
\hline $13: 45$ & 2.25 & 2.18 & 3.11 & 17.63 & 17.48 & 0.85 \\
\hline $14: 00$ & 3.56 & 3.46 & 2.81 & 17.51 & 17.29 & 1.26 \\
\hline $14: 15$ & 4.93 & 4.76 & 3.45 & 17.38 & 17.09 & 1.67 \\
\hline $14: 30$ & 6.27 & 6.10 & 2.71 & 17.25 & 16.88 & 2.14 \\
\hline $14: 45$ & 7.67 & 7.50 & 2.22 & 17.10 & 16.64 & 2.69 \\
\hline \multicolumn{3}{|c|}{ Mean absolute diff. } & 3.32 & Mean absolute & & 1.16 \\
\hline
\end{tabular}




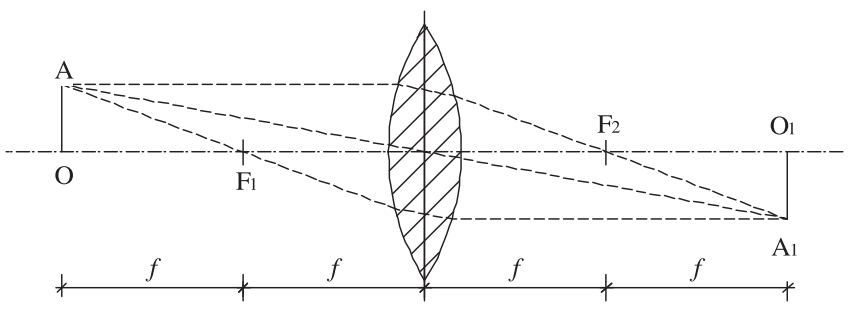

Fig. 11. Optical behaviour of an ideal converging lens.

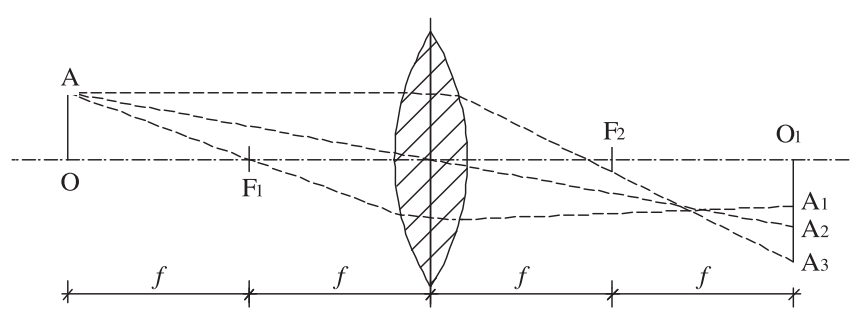

Fig. 12. Optical behaviour of a real converging lens.

of the lens, include spherical aberration, coma, astigmatism and distortion. Chromatic aberrations are caused by the variation of a lens's refractive index with wavelength.

Due to the spherical aberration a ray parallel to, but distant from, the lens axis is focused in a slightly different place than a ray close to the axis; rays parallel to the lens axis converge into points that are different from the focal point of the lens. When a bundle of parallel rays, which are not parallel to the lens axis, are focused by a lens, the image is affected by coma, which derives its name from the cometlike appearance of the aberrated image. Astigmatism is the aberration present when an oblique bundle of rays impinges on the lens from a point not on the optical axis of the lens. Due to astigmatism the lens produce an image which consists of two coaxial warped and irregular surfaces.

The above aberrations are mainly due to the fact that spherical surfaces are not the ideal shape with which to make a lens; actually spherical lenses are widely used because they are the simplest way to pattern glass. Spherical aberration and coma can be reduced by using a diaphragm with a stop, which is an opaque plate perforated with a small central aperture. The stop should prevent the transmission of any but those rays that are close to the axis of the lens.

In order to approximate the paraxial condition by eliminating the marginal rays, the stop should be put very close to the lens as it is shown in Fig. 13.

In many practical situations the stop cannot be placed very close to the lens and for this reason the image may be affected by distortion. As it is depicted in Figs. 14 and 15 , where two different positions of the stop are shown, due to the presence of marginal rays the lens does not respect the fourth property of the Gaussian theory: the image does not have the same dimensions of the object.

Moreover the image is not orthoscopic because the magnification ratio of the optical systems varies with the distance from the lens axis. As a consequence, the images of

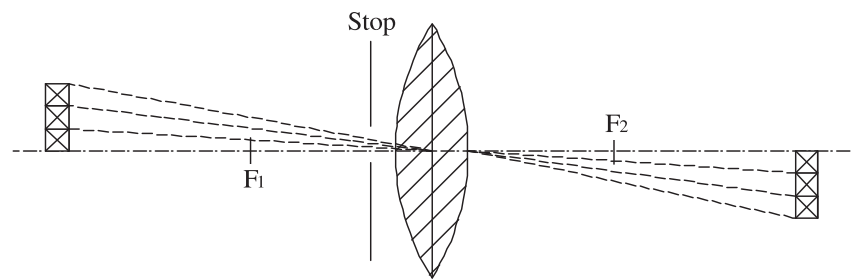

Fig. 13. Optical behaviour of a lens in paraxial conditions.

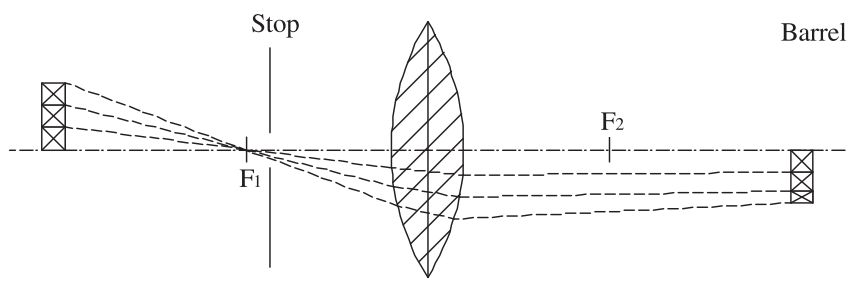

Fig. 14. Effect of a stop located in front of a lens.

the objects are distorted and the geometrical rules of linear perspective are not obeyed. The configurations of Figs. 14 and 15 , respectively lead to the barrel and pincushion distortions that change a regular lattice into the shapes shown in Fig. 16.

Even the human eye may be affected by distortion. For this reason only a very small area of the retina, which is called fovea, is particularly sensitive. Moreover the iris behaves like a stop. The fovea covers about two degrees of visual angle in people. In this way the Gaussian paraxial conditions are reached and a minimal distortion is produced. Ancient Greek architects had realised that long horizontal lines of a temple tend to make the optical impression of sagging downwards and the vertical lines of sloping outwards. In order to counterbalance distortions of human visual perception the horizontal lines of stylobate and entablature were usually raised upwards and the columns were tilted inwards.

Figs. 14 and 15 only are a schematic representation of distortion. Camera lenses are more complicate than a simple convex lens; actually a compound lens made up of a number of optical lens elements is required to reduce optical aberrations. The aberration can be minimised when the camera lenses have a symmetrical disposition. Unfortunately the symmetrical disposition does permit to reach the high optical performances of modern camera lenses. Telephoto lenses generally show pincushion distortion. Retrofocus wide angle lenses are extremely asymmetric and therefore very difficult to correct for distortion. No attempt is made to correct fisheye lenses for distortion. Zoom lenses have a distortion varying from barrel at the wide-end to pincushion at the tele-end. In camera lenses distortion also depends on the object distance and can assume a more complex shape, called moustache distortion, that is a mixture of barrel and pincushion distortion. Moustache distortion starts out as a barrel distortion close to the image centre and turns into pincushion distortion towards the image periphery. 


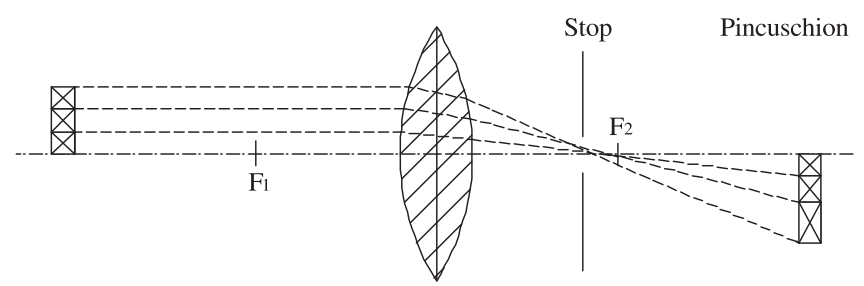

Fig. 15. Effect of a stop located at the back of a lens.
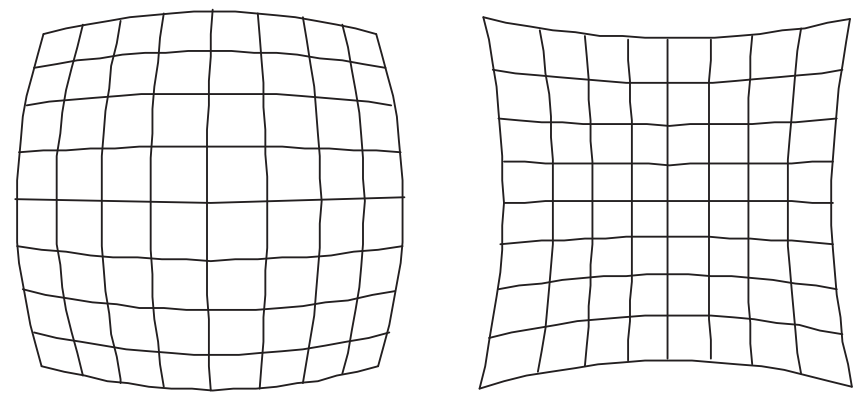

Fig. 16. Barrel and pincushion distortion of a lattice.

Only some important manufacturers provide information about the distortion of their camera lenses. The distortion is expresses as the difference between the distances from the image centre to the corners of the distorted and undistorted grids. The information is given in form of graphs reporting the relative distortion versus the distance from the image centre; relative distortion is the percentage ratio of the distortion and the distance from the image centre to the corner of the undistorted grid. A positive slope of the relative distortion curve implies pincushion distortion, a negative slope barrel distortion. The shapes of the curves reported in the graphs provided by manufacturers, whose slope usually changes its sign with the distance from the image centre, highlight the complexity of the theoretical study of distortion.

First attempts to study the possibility of analytically removing distortion were made by Conrady (1919) and Brown $(1966,1971)$ who proposed the following distortion model:

$$
\begin{aligned}
x_{u}= & x_{d}+\left(x_{d}-x_{c}\right)\left(K_{1} r^{2}+K_{2} r^{4}+\cdots\right)+\left\{P _ { 1 } \left[r^{2}\right.\right. \\
& \left.\left.+2\left(x_{d}-x_{c}\right)^{2}\right]+2 P_{2}\left(x_{d}-x_{c}\right)\left(y_{d}-y_{c}\right)\right\}\left(1+P_{3} r^{2}\right. \\
& +\cdots) \\
y_{u}= & y_{d}+\left(y_{d}-y_{c}\right)\left(K_{1} r^{2}+K_{2} r^{4}+\cdots\right)+\left\{P _ { 2 } \left[r^{2}\right.\right. \\
& \left.\left.+2\left(y_{d}-y_{c}\right)^{2}\right]+2 P_{1}\left(x_{d}-x_{c}\right)\left(y_{d}-y_{c}\right)\right\}\left(1+P_{3} r^{2}\right. \\
& +\cdots)
\end{aligned}
$$

where $\left(x_{u}, y_{u}\right)$ are the coordinates of the undistorted image point, $\left(x_{d}, y_{d}\right)$ of the coordinates of the distorted image point and $\left(x_{v}, y_{c}\right)$ are the coordinates of the centre of distortion; $K_{n}$ and $P_{n}$ are the $n$th radial and tangential coefficients, respectively, and: $r=\sqrt{\left(x_{d}-x_{c}\right)^{2}+\left(y_{d}-y_{c}\right)^{2}}$

is the radial distance from the image centre. Eqs. (10) and (11) can be used to determine where a point in the distorted image would appear in the image plane if there was no lens distortion. Typically, only one or two distortion parameters are used because higher order terms are comparatively insignificant.

Further methods to face the problem of optical distortion have been proposed. First family of methods uses a calibration grid with feature points whose world 3D coordinates are known. These feature points are usually dots or corners that can be easily extracted from the image of a calibration object whose geometrical structure is accurately known. Some procedures based on this approach have been recently proposed (Wang et al., 2008; RicolfeViala and Sánchez-Salmerón, 2010; Krüger and Wöhler, 2011). Second approach is based on the use of geometric invariants of the image features like parallel lines or the image of spheres or rectangles. Some recent examples were given by Kim and Kweon (2009), Zhao and Liu (2010) and $\mathrm{Lu}$ and Payandeh (2010). Further methods, which consider the geometrical properties of perspective, are based on the position of vanishing points of the image (Grammatikopulos et al., 2007; Avinash and Murali, 2008; $\mathrm{He}$ and Li, 2008). Solar shadows were also used by Kawasaki and Furukawa (2009), Junejo and Foroosh (2010) and Wu et al. (2010) to correct distortion from images. Finally, the self-calibration approach, which does not need known calibration points, has been analysed. Some recent self-calibration methods were proposed by Habed and Boufama (2008), Menudet et al. (2008) and Ramalingam et al. (2010).

Because lens distortion is a significant problem while using digital images, numerous software (Adobe Photoshop; Altostorm Rectilinear Panorama; DxO Optics Pro; Elcovision; PerspectivePilot; PTLens) are available in order to correct distortion of images in post-production. Modern digital cameras are often equipped with computer software loaded with information on the specific camera and lenses.

In order to investigate the observed differences between the photographed and the calculated sun's positions, a survey of the possible causes was carried out. It is possible to identify the following different origins:

- The experimental inaccuracies related to the imperfect horizontal placement of the camera, slight displacements of the tripod or imprecise measurements of the angles.

- The computation errors mainly due to the equations used to describe the solar declination and the equation of time.

- The optical discrepancies induced by the lenses distortion of the image.

To reduce the experimental inaccuracies, a precision tacheometer was used for the experimental verification in 
the field. A small impact is ascribable to computation errors because the equations used for the solar declination and the equation of time are traditionally considered very reliable. As a consequence, the optical distortion of the photographs may be the main cause of the differences between the photographed and the calculated sun's positions. To eliminate the effects of optical distortion, the photographs should be corrected by means of the calibration methods that have been proposed to solve the problem.

This paper does not aim to face the complex problem of camera calibration. Nevertheless, an attempt to highlight the impact of the optical distortion was made. For this purpose the photographs of obstructions were compared with the images of the same objects drawn following the geometrical rules of perspective. Obviously, to get a correct comparison between the photograph and the corresponding perspective drawing the point of view was assumed to be placed in the same point were the camera was located. Moreover the real dimensions of the photographed object and their distances from the camera were accurately considered. The effects of optical distortion are shown in Figs. 17 and 18, in which the perspective outlines of the building are represented with dotted lines.

It is easy to observe that the perspective outlines does not coincide with the photographed buildings. Because the solar discs of Figs. 9 and 10 were photographed, they are affected by the same distortion that is present in the photographs of the building. For a correct check of the proposed method, the undistorted photographs of the sun discs should be matched with the calculated sun's position. To reach such a purpose, Adobe Photoshop ${ }^{\mathrm{TM}}$ and Vectorworks ${ }^{\mathrm{TM}}$ were used to rework the photographs in order to make them superimposable on the building's outlines, which were drawn obeying the perspective rules. As it is shown in Fig. 19, when the reworked photograph overlaps the perspective outline of the building, also the photographed solar discs and the calculated sun's positions

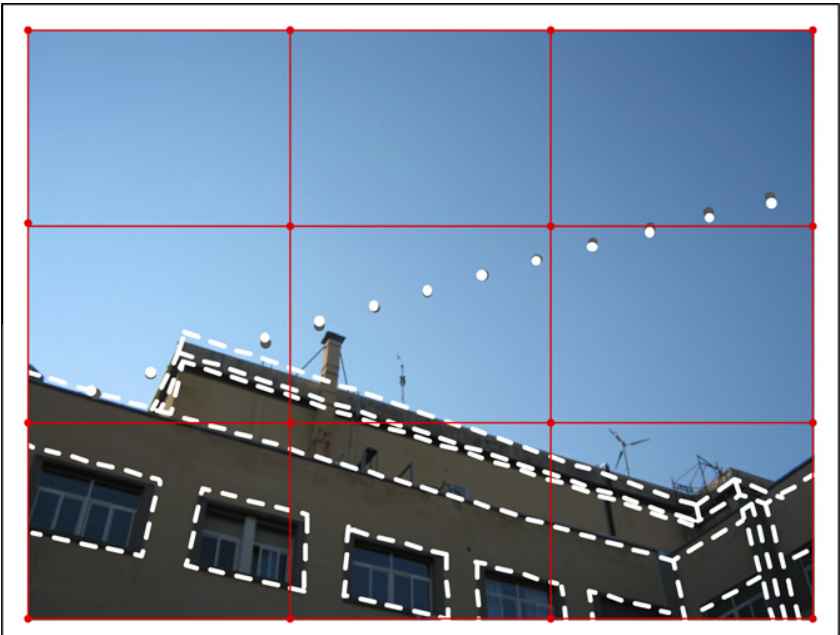

Fig. 17. Comparison between the photograph of Fig. 7 and the perspective outline of the building.

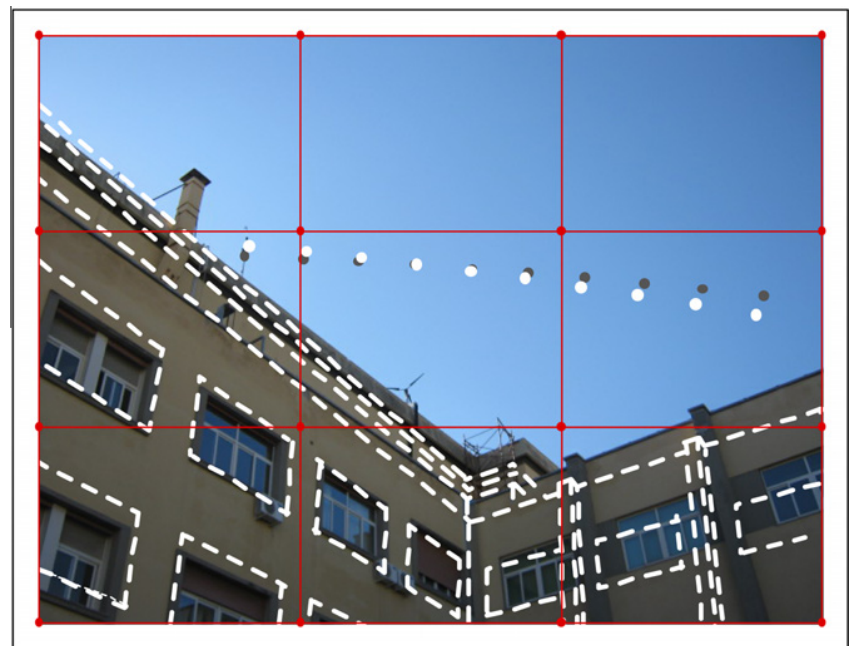

Fig. 18. Comparison between the photograph of Fig. 8 and the perspective outline of the building.

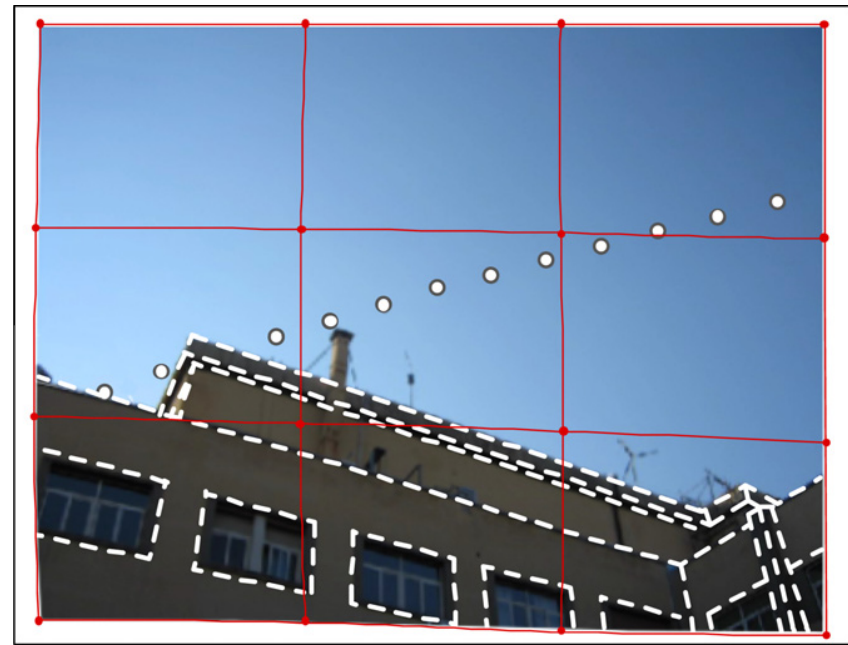

Fig. 19. Comparison between the manipulated photograph of Fig. 8 and the perspective outline of the building.

perfectly coincide. The deformation of the grid, which is stuck on the photograph, highlights the effect of the reworking.

The reworking of the photograph has completely compensated the distortion and the incorrect horizontal positioning of the camera. Observing Fig. 19 is also possible to infer that the photograph of Fig. 7 was affected by a small pincushion distortion because it was necessary to bring the corners of the image close to the centre. The result of an analogous procedure applied to Fig. 8 is shown in Fig. 20.

In this case, to overlap the photograph to the perspective outline, it was necessary to expand the upper corners of the photographic image; the opposite was made for the right lower corner of the photograph. The image of Fig. 8 was affected by a mix of barrel and pincushion distortion. 


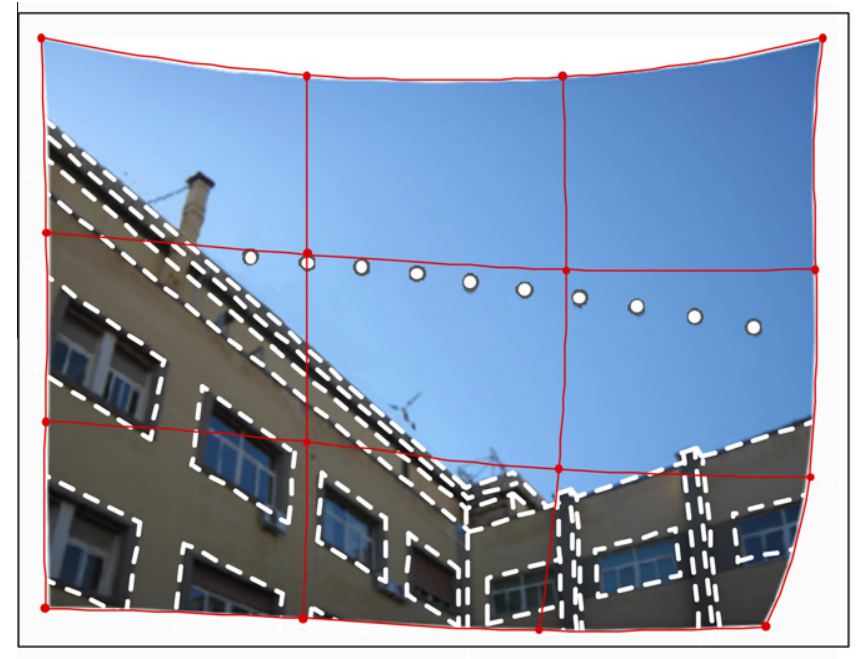

Fig. 20. Comparison between the manipulated photograph of Fig. 9 and the perspective outline of the building.

Due to the complex nature of distortion it is not amazing that two photographs taken by the same camera are affected by a different kind of distortion. The reworking of the photographs permits to assert that the proposed method is not affected by computational errors and that the observed small inaccuracies only have an experimental and optical origin. Ordinary cameras with a focal length of $50 \mathrm{~mm}$, as we used, produce the little distortion shown in Figs. 17 and 18. Depending on the season, the shape of the obstructions and the distance from the observer point, a number of photographs varying from 1 to 4 may be necessary to include the whole daily sun's path for a site with the same latitude of Palermo. A smaller number of photographs would be necessary if a wide-angle lens, whose angle of view covers more than $180^{\circ}$, was used.
Wide-angle lenses are classified depending on their mapping function that permits to evaluate for a sideways object the position displacement of its image from the centre of the photograph. These lenses can have several mapping function (orthographic, stereographic, equisolid angle, linear scaled, etc.) that bend straight lines by means of simple trigonometric relations. Fisheye lenses have focal lengths varying from 8 to $16 \mathrm{~mm}$ and generally suffer from barrel distortion. The distortion increases when the focal length is shorter and the angle of view is larger. Moreover cameras provided by fish-eye lenses are more expensive than ordinary cameras with a focal length of $50 \mathrm{~mm}$ and the remarkable deformation of the images, which is due to the mapping function, may complicate the interpretation of results and confuse the users. For this reason the photographs taken with fisheye lenses are quite unsuited for the proposed method.

In conclusion, if applied to photographs taken with ordinary cameras the method can be considered adequately reliable and effective because the differences between the photographed and the calculated sun's positions correspond to very small time lags that do not exceed few minutes in the worst case.

\subsection{Available web tool}

In order to promote the use of the proposed method, the authors provide a computer program called Photo Sun Track that is available entering the web site www.dream.unipa.it/2012/percorsisolari/ (Fig. 21).

Photo Sun Track automatically evaluates the sun's positions corresponding to the latitude and longitude of the site, the selected day and angular data $\varphi_{\text {cam }}$ (azimuth), $\beta_{M}$ (altitude 1) and $\beta_{N}$ (altitude 2). After have uploaded the photograph, points 1 and 2 can be set simply clicking into the image (Fig. 22).

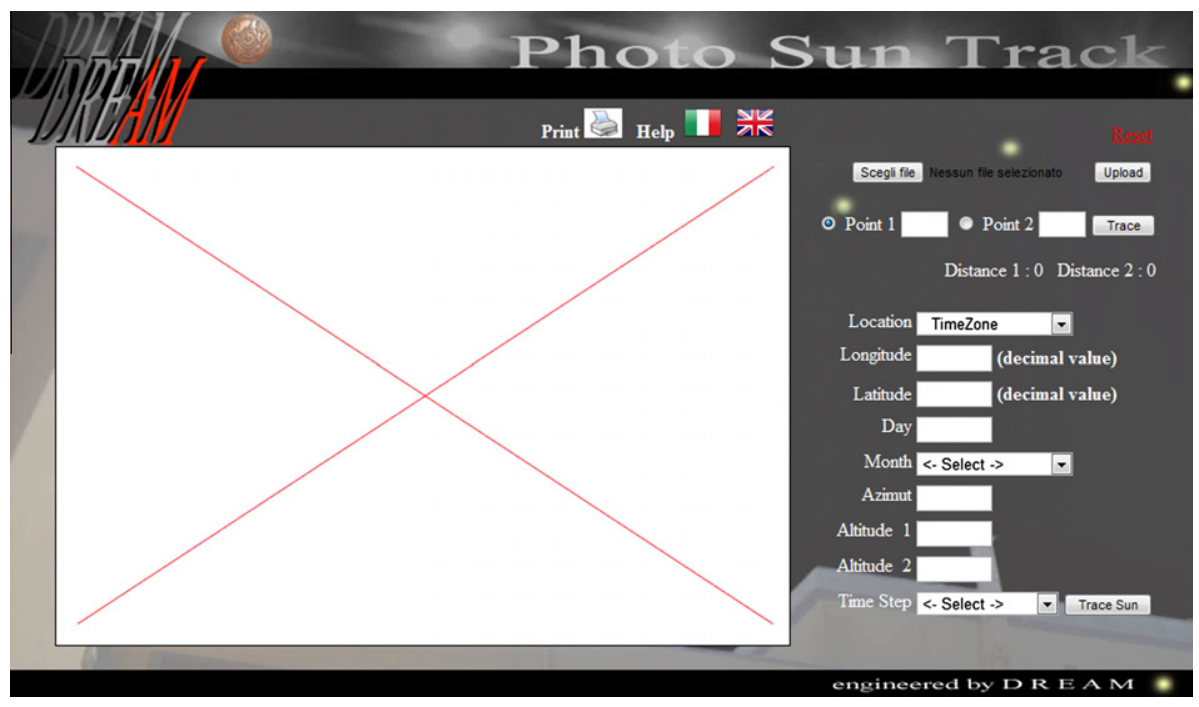

Fig. 21. Home page of Photo Sun Track software. 


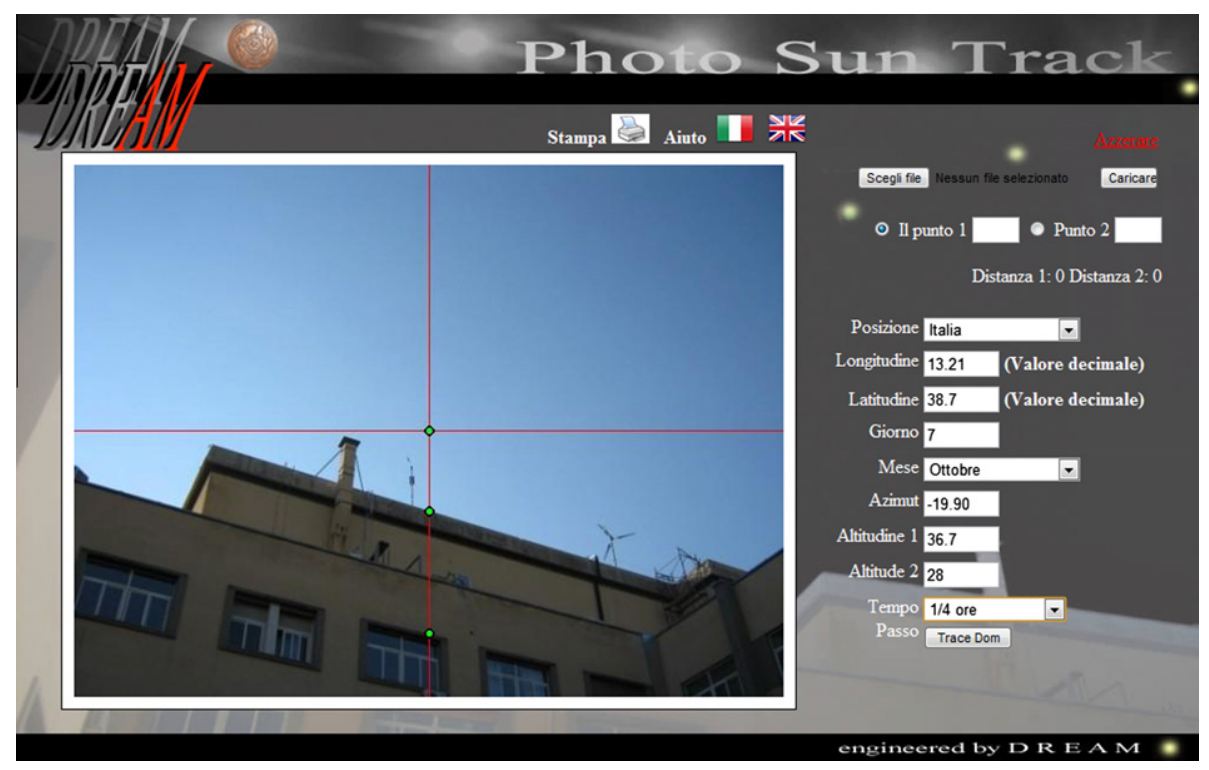

Fig. 22. Input data set of Photo Sun Track software.

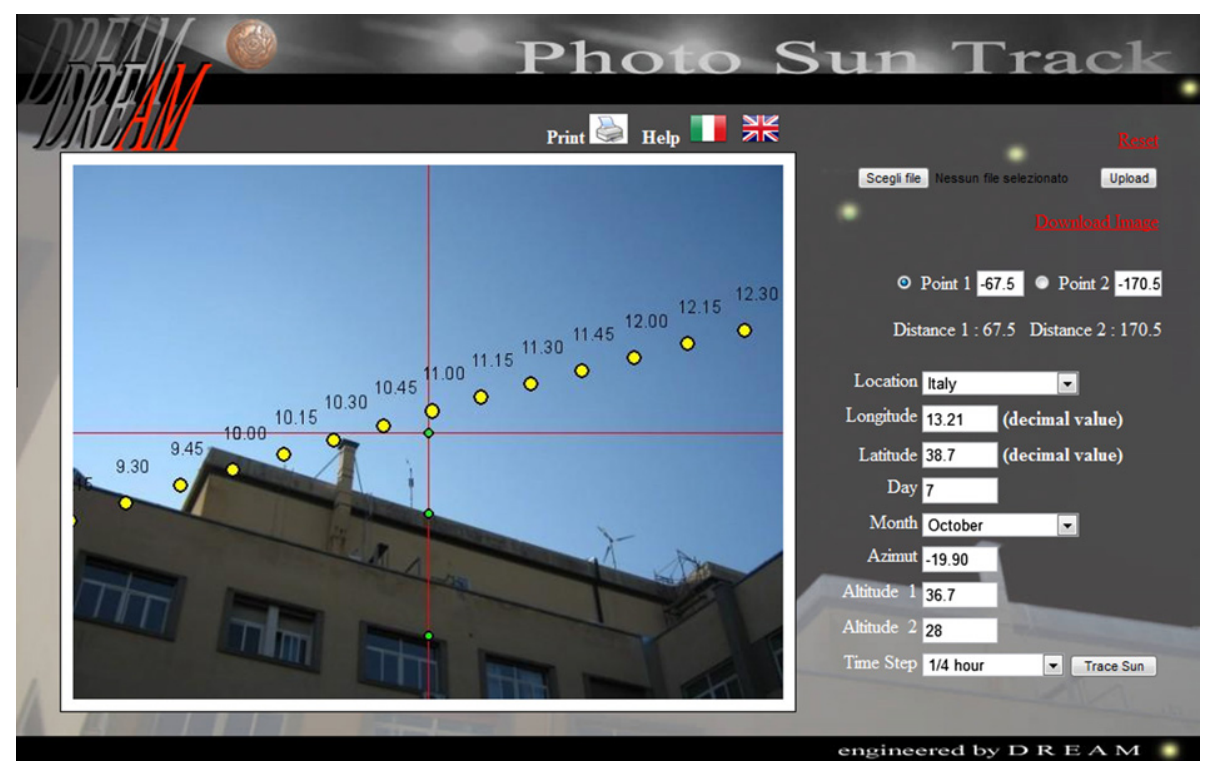

Fig. 23. Results of calculations performed by Photo Sun Track software.

As it is depicted in Fig. 23, Photo Sun Track is able to overlap on the photograph the calculated sun's positions corresponding to the time step chosen by the user. A printed report of the results is also available.

\section{Conclusions}

The accurate evaluation of the solar irradiance is of primary concern because it allows the designer to optimise the system energy performance. The identification of the irradiance value, while considering the effect of the shading surfaces, is not an easy task. In fact, it is very difficult to precisely determine shading caused by surroundings because the outside environment is crowded by many objects that have different and complex shapes. Even though calculations are facilitated by powerful software tools, a large input data set is generally needed for a sharp description of the objects' geometry.

To overcome these problems a new photographic method is proposed to estimate the shading effects of obstructions. The method uses the photographs of the surrounding objects as the backgrounds on which the solar disc is depicted at the various hours of the day. Despite the complex mathematical background of the new tool, its practical application is very simple and only requires the measurements of three angles for each photograph. For rough calculations the angles can be measured with a compass and a clinometer. 
The accuracy of the method was tested by performing an experimental verification. For this purpose, the sun was photographed by a camera at different hours of the day. The shots of the solar disc at the various hours were overlapped and compared to the sun's positions calculated with the proposed procedure. The differences between the photographed and calculated positions corresponded to small time lags that do not exceed a few minutes.

To further test the reliability of the proposed method the effect of image distortion was examined. Optical aberration, named distortion, causes images that do not obey the linear perspective rules on which the proposed method is based. To highlight the effect of distortion, the outline of the photographed buildings were drawn following the perspective rules and compared with the photographs. As it was expected, due to distortion the perspective outlines imperfectly overlap the photographed buildings; for the same reason the calculated sun's positions do not correspond to the shots of the solar disc. Photoshop ${ }^{\mathrm{TM}}$ and Vectorworks ${ }^{\mathrm{TM}}$ were used to rework the photographs in order to make them superimposable on the perspective outlines of buildings. It was observed that if the reworked photograph overlaps the perspective outline of the building, also the photographed solar discs and the calculated sun's positions perfectly coincide. If applied to photographs taken with ordinary cameras with a focal length of $50 \mathrm{~mm}$, the method results very reliable and effective. Because distortion increases when the focal length decreases, the photographs taken with wide angle lenses are quite unsuited for the proposed method.

\section{Appendix A. Evaluation of solar altitude and solar azimuth angles}

For a generic site whose geographic coordinates are known, the sun's position in the sky can be conveniently expressed in terms of solar altitude $\beta_{S}$ above the horizontal plane and solar azimuth $\varphi_{S}$ measured from the south (Fig. A1).

A positive azimuth angle indicates that the sun is southwest; a negative azimuth angle indicates that the sun is southeast. These angles depend on the local latitude $L$, the solar declination $\delta$, and the apparent solar time as expressed as the hour angle $H$ (ASHRAE Handbook Fundamental, 2009):

$\beta_{S}=\arcsin (\cos L \cos \delta \cos H+\sin L \sin \delta)$

$\varphi_{S}=\arccos \left(\frac{\cos H \cos \delta \sin L-\sin \delta \cos L}{\cos \beta_{S}}\right)$

The hour angle can be calculated with the expression:

$H=15(A S T-12)$

where the apparent solar time $A S T$ is:

$A S T=L S T+E T / 60+(L S M-L O N) / 15$

in which $L S T$ is related to the local standard time, $E T$ is the equation of time, $L S M$ is the local standard time meridian

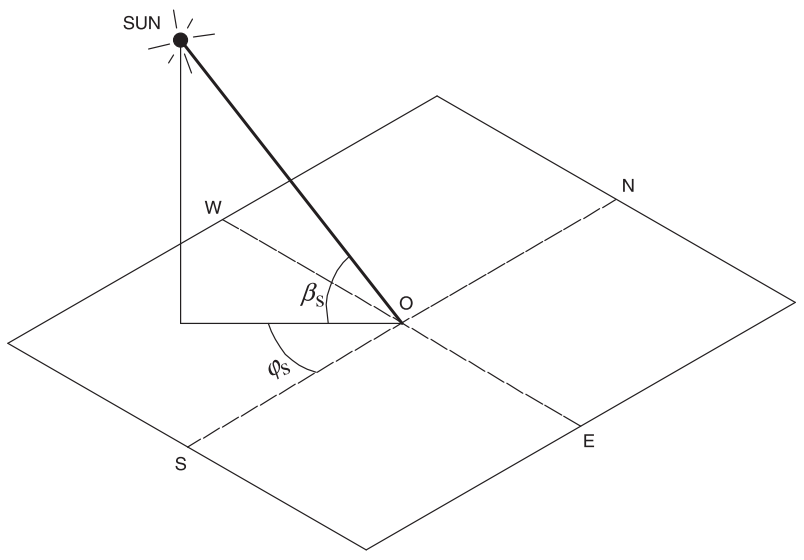

Fig. A1. Solar angles.

and $L O N$ is the local longitude. The solar declination and the equation of time can be evaluated using the following equations (Carruthers et al., 1990):

$$
\begin{gathered}
\delta=a_{0}+a_{1} \cos \left(t_{\delta}\right)+a_{2} \cos \left(2 t_{\delta}\right)+a_{3} \cos \left(3 t_{\delta}\right)+ \\
a_{4} \sin \left(t_{\delta}\right)+a_{5} \sin \left(2 t_{\delta}\right)+a_{6} \sin \left(3 t_{\delta}\right)
\end{gathered}
$$

in which:

$$
\begin{array}{cl}
t_{\delta}=2 \pi \frac{n_{d a y}}{366} & a_{0}=0.322003 \\
a_{1}=-22.971 & a_{2}=-0.357898 \\
a_{3}=-0.14398 & a_{4}=3.94638 \\
a_{5}=0.019334 & a_{6}=0.05928
\end{array}
$$

and:

$$
\begin{gathered}
E T=b_{0}+b_{1} \sin \left(t_{E T}\right)+b_{2} \sin \left(2 t_{E T}\right)+b_{3} \sin \left(3 t_{E T}\right)+ \\
b_{4} \sin \left(4 t_{E T}\right)+b_{5} \cos \left(t_{E T}\right)+b_{6} \cos \left(2 t_{E T}\right)+b_{7} \cos \left(3 t_{E T}\right)
\end{gathered}
$$

in which:

$$
\begin{array}{ll}
t_{\delta}=2 \pi \frac{n_{\text {day }}}{366} & a_{0}=0.322003 \\
a_{1}=-22.971 & a_{2}=-0.357898 \\
a_{3}=-0.14398 & a_{4}=3.94638 \\
a_{5}=0.019334 & a_{6}=0.05928
\end{array}
$$

where $n_{\text {day }}$ is the day of the year ( 1 for January 1, 32 for February 1, etc.).

As it is shown in Fig. A2, the sun's position on a vertical picture plan can be determined using the following equations:

$$
\overline{O V}=d \quad \overline{O S^{\prime}}=d \tan (\varphi) \quad \overline{S S^{\prime}}=d \frac{\tan \left(\beta_{S}\right)}{\cos (\varphi)}
$$

in which $d$ is the distance between the observer and the picture plane, $\beta_{S}$ is the solar altitude and $\varphi$ is the relative solar azimuth, i.e. the difference between the solar azimuth $\varphi_{S}$ and the azimuth of the central visual ray line. The direction of the central visual ray line, which corresponds to the 


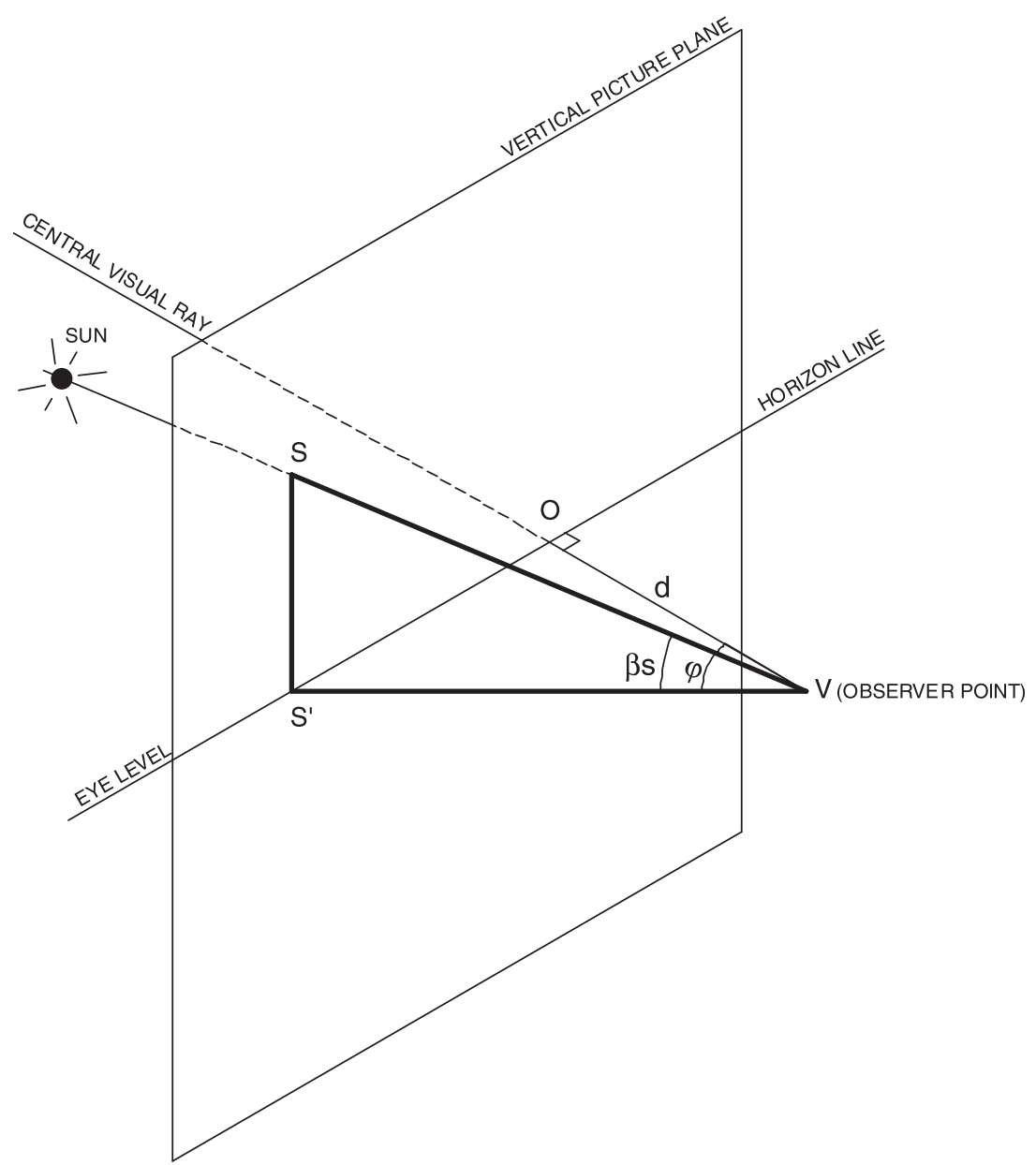

Fig. A2. Sketch of the sun's position on a vertical picture plane.

direction in which the camera is pointing, is defined by the azimuth angle $\varphi_{\text {cam }}$.

With an inclined picture plane the sun's position in the picture can be evaluated by pivoting the picture plane around the horizon line of the picture. Point $T$, which represents the sun's position on an inclined picture plane, can be easily evaluated using the analytic geometry of space. For this purpose, we use a three-dimensional orthogonal coordinate system shown in Fig. 6, which places the origin on the horizon line. The standard equation of a plane in a three-dimensional space is:

$m x+n y+p z+q=0$

Coefficients $m, n, p$ and $q$ for the pivoted plane can be determined by assuming that the following points $P_{1}, P_{2}$ and $P_{3}$ :

$P_{1} \equiv(0,0,0) \quad P_{2} \equiv(0,1,0) \quad P_{3} \equiv(\sin \gamma, 0, \cos \gamma)$

belong to the plane. It easy to verify that this position yields:

$\frac{q}{p}=0 \quad \frac{n}{p}=0 \quad \frac{m}{p}=-\frac{\cos \gamma}{\sin \gamma}$ and, consequently, the equation of the plane pivoted around the $y$-axis by the angle $\gamma$ is:

$\frac{x}{\tan \gamma}-z=0$

To determine point $T$, we write the equation of the line containing points $V$ and $S$ that, in the three-dimensional orthogonal coordinate system of Fig. 6, are expressed by:

$V \equiv[d, 0,0] \quad S \equiv\left[0, d \tan (\varphi), d \frac{\tan \left(\beta_{S}\right)}{\cos (\varphi)}\right]$

The equation of the line containing points $V$ and $S$ can be obtained by verifying the standard equation of the line in a three-dimensional space:

$\frac{x-x_{V}}{x_{S}-x_{V}}=\frac{y-y_{V}}{y_{S}-y_{V}}=\frac{z-z_{V}}{z_{S}-z_{V}}$

in which $x_{V}, y_{V}, z_{V}$ and $x_{S}, y_{S}, z_{S}$ are the coordinates of points $V$ and $S$ indicated in Eq. (A12). The following equations are derived by Eq. (A13):

$\left\{\begin{array}{l}x+\frac{1}{\tan (\varphi)} y-d=0 \\ x+\frac{\cos (\varphi)}{\tan \left(\beta_{S}\right)} z-d=0\end{array}\right.$ 
By solving the system of Eq. (A11) and Eq. (A14), it is possible to determine the coordinates of point $T$ :

$$
\begin{aligned}
& x_{T}=\frac{d \tan \left(\beta_{S}\right) \tan (\gamma)}{\tan \left(\beta_{S}\right) \tan (\gamma)+\cos (\varphi)} \\
& y_{T}=\frac{d \sin (\varphi)}{\tan \left(\beta_{S}\right) \tan (\gamma)+\cos (\varphi)} \\
& z_{T}=\frac{d \tan \left(\beta_{S}\right)}{\tan \left(\beta_{S}\right) \tan (\gamma)+\cos (\varphi)}
\end{aligned}
$$

The position of point $T$ referred to the inclined picture plane is defined by the following expressions:

$$
\begin{aligned}
& \overline{O T^{\prime \prime}}=\frac{d \tan \left(\beta_{S}\right) \tan (\gamma)}{\tan \left(\beta_{S}\right) \tan (\gamma)+\cos (\varphi)} \\
& \overline{T T^{\prime \prime}}=\frac{d \sin (\varphi)}{\left[\tan \left(\beta_{S}\right) \tan (\gamma)+\cos (\varphi)\right] \cos (\gamma)}
\end{aligned}
$$

\section{References}

Adobe Photoshop. $<$ http://www.adobe.com/products/photoshop.html $>$. Altostorm Rectilinear Panorama, <http://www.altostorm.com/>.

Ashrae Handbook - Fundamentals, 2009. American Society of Heating, Refrigerating and Air-Conditioning Engineers, Inc., Atlanta, GA, USA.

Avinash, N., Murali, S., 2008. Perspective geometry based single image camera calibration. J. Math. Imag. Vision 30 (3), 221-230.

Awnshade. $<$ http://www.fsec.ucf.edu $>$.

Brown, D.C., 1966. Decentering distortion of lenses. Photogramm. Eng. 32 (3), $444-462$.

Brown, D.C., 1971. Close-range camera calibration. Photogramm. Eng. 37 (8), 855-866.

Caamaño, E., Lorenzo, E., 1997. On-site characterisation of gridconnected PV systems. In: Proceedings of the 14th EC PV Solar Energy Conference, Barcelona, pp. 1536-1539.

Capelluto, I.G., Shaviv, E., 2001. On the use of "solar volume" for determining the urban fabric. Sol. Energy 70 (3), 275-280.

Carruthers, D.D., Roy, G.G., Uloth, C.J., 1990. An evaluation of formulae for solar declination and the equation of time. Research Report No 17, School of Architecture, University of Western Australia.

Cellura, M., Orioli, A., Di Gangi, A., 2012. A photographic method to estimate the shading effect of obstructions. Sol. Energy 86, 886-902.

Chaabene, M., Ben Ammar, M., 2008. Neuro-fuzzy dynamic model with Kalman filter to forecast irradiance and temperature for solar energy systems. Renew. Energy 33 (7), 1435-1443.

Chang, T.P., 2009. The sun's apparent position and the optimal tilt angle of a solar collector in the northern hemisphere. Sol. Energy 83 (8), 1274-1284.

Cheung, H.D., Chung, T.M., 2007. Analyzing sunlight duration and optimum shading using a sky map. Build. Environ. 42 (9), 3138-3148.

Compagnon, R., 2004. Solar and daylight availability in the urban fabric. Energy Build. 36 (4), 321-328.

Conrady, A.E., 1919. Decentered lens systems. Mon. Not. R. Astron. Soc. 79, 384-390.

Drif, M., Perez, P.J., Aguilera, J., Aguilar, J.D., 2008. A new estimation method of irradiance on partially shaded PV generator in gridconnected photovoltaic systems. Renew. Energy 33 (9), 2048-2056.

DxO Optics Pro. <http://www.dxo.com/us/photo/dxo_optics_pro/ optics_geometry_corrections $>$.

Ecotect. $<$ http://www.squ1.com $>$.

Elcovision. $<$ http://www.elcovision.com/e_index.html $>$.

Frei, R., Meier, C., Eichenberger, P., 2000. A fast, efficient and reliable way to determine the PV-shading horizon. In: Proceedings of the 16th EC PV Solar Energy Conference, Glasgow, pp. 2678.

Gomez-Munoz, V.M., Porta-Gandara, M.A., 2003. General model to build awnings and external walls with optimum shading interaction. Renew. Energy 29 (4), 605-613.
Grammatikopulos, L., Karras, G., Petsa, E., 2007. An automatic approach for camera calibration from vanishing points. Photogramm. Remote Sens. 62 (1), 64-76.

Grochowski, J., Fuge, U., Niehage, M., 1997. STASOL Ein Programm zur Simulation der Solarstrahlung unter Berücksichtigung von Teilabshattungen der Diffusend Direktstrahlung. In: Proceedings of the 12th Symposium Photoltaische Solarenergie, Staffelstein, pp. 106-110.

Gueymard, C., 1987. An anisotropic solar irradiance model for tilted surfaces ant its comparison with selected engineering algorithms. Sol. Energy 38 (5), 367-386.

Gueymard, C.A., 2001. Parameterized transmittance model for direct beam and circumsolar spectral irradiance. Sol. Energy 71 (5), 325-346.

Gueymard, C.A., 2003a. Direct solar transmittance and irradiance predictions with broadband models. Part I: detailed theoretical performance assessment. Sol. Energy 74 (5), 335-379.

Gueymard, C.A., 2003b. Direct solar transmittance and irradiance predictions with broadband models. Part I: validation with highquality measurements. Sol. Energy 74 (5), 381-395.

Habed, A., Boufama, B., 2008. Camera self-calibration from bivariate polynomials derived from Kruppa's equations. Pattern Recogn. 41 (8), 2484-2492.

Hay, J.E., Davies, J.A., 1980. Calculations of the solar radiation incident on an inclined surface. In: Hay J.E., Won, T.K. (Eds.), Proc. of First Canadian Solar Radiation Data Workshop, 59. Ministry of Supply and Services, Canada.

He, B.W., Li, Y.F., 2008. Camera calibration from vanishing points in a vision system. Opt. Laser Technol. 40 (3), 555-561.

Jenkins, F.A., White, H.E., 1976. Fundamentals of Optics, fourth ed. McGraw-Hill.

Junejo, I.N., Foroosh, H., 2010. GPS coordinates estimation and camera calibration from solar shadows. Comput. Vis. Image Underst. 114 (9), 991-1003.

Kawasaki, H., Furukawa, R., 2009. Shape reconstruction and camera selfcalibration using cast shadows and scene geometries. Int. J. Comput. Vision 83 (2), 135-148.

Kim, J., Kweon, I., 2009. Camera calibration based on arbitrary parallelograms. Comput. Vis. Image Underst. 113 (1), 1-10.

Klucher, T.M., 1979. Evaluation of models to predict insolation on tilted surfaces. Sol. Energy 23 (2), 111-114.

Knowles, R.L., 2003. The solar envelope: its meaning for energy and buildings. Energy Build. 35 (1), 15-25.

Kovach, A., Schmid, J., 1996. Determination of energy output losses due to shading of building-integrated photovoltaic arrays using a raytracing technique. Sol. Energy 57 (2), 117-124.

Krüger, L., Wöhler, C., 2011. Accurate chequerboard corner localisation for camera calibration. Pattern Recogn. Lett. 32 (10), 1428-1435.

Leso-Shade. <http://lesowww.epfl.ch/>.

Levinson, R., Akbari, H., Pomerantz, M., Gupta, S., 2009. Solar access of residential rooftops in four California cities. Sol. Energy 83 (12), 2120 2135.

Littefair, P., 1998. Passive solar urban design: ensuring the penetration of solar energy into the city. Renew. Sustain. Energy Rev. 2 (3), $303-$ 326 .

Littefair, P., 2001. Daylight, sunlight and solar gain in the urban environment. Sol. Energy 70 (3), 177-185.

Littefair, P., 2002. Daylight prediction in atrium buildings. Sol. Energy 73 (2), 105-109.

Lopez, G., Batlles, F.J., Tovar-Pescador, J., 2005. Selection of input parameters to model direct solar irradiance by using artificial neural networks. Energy 30 (9), 1675-1684.

Loutzenhiser, P.G., Manz, H., Felsmann, C., Strachan, P.A., Frank, T., Maxwell, G.M., 2007. Empirical validation of models to compute solar irradiance on inclined surfaces for building energy simulation. Sol. Energy 81 (2), 254-267.

Louver Shading. $<$ http://www.susdesign.com $>$.

Lu, Y., Payandeh, S., 2010. On the sensitivity analysis of camera calibration from images of spheres. Comput. Vis. Image Underst. 114 (1), 8-20. 
Mardaljevic, J., Rylatt, M., 2003. Irradiation mapping of complex urban environments: an image-based approach. Energy Build. 35 (X), 27-35.

Mellit, A., Eleuch, H., Benghanem, M., Elaoun, C.Massi., Pavan, A., 2010. An adaptive model for predicting of global, direct and diffuse hourly solar irradiance. Energy Convers. Manage. 51 (4), 771-782.

Menudet, J.F., Becker, J.M., Fournel, T., Mennessier, C., 2008. Planebased camera self-calibration by metric rectification of images. Image Vis. Comput. 26 (7), 913-934.

Muneer, T., 1997. Solar Radiation and Daylight Models for the Energy Efficient Design of Buildings. Architectural Press, Oxford.

Ordonez, C., Arias, P., Herraez, J., Rodriguez, J., Martin, M.M., 2008. Two photogrammetric methods for measuring flat elements in buildings under construction. Automat. Construct. 17, 517-525.

Overhang Annual Analysis. <http://susdesign.com/overhang annual $>$.

Overhang Design. $<$ http://www.susdesign.com $>$.

Panel Shading, $<$ http://www.susdesign.com $>$.

ParaSol. <http://www.parasol.se $>$.

Perez, R., Stewart, R., Arbogast, C., Seals, R., Scott, J., 1986. An anisotropic hourly diffuse radiation model for sloping surfaces: description, performance validation, site dependency evaluation. Sol. Energy 36 (6), 481-497.

Perez, R., Seals, R., Ineichen, P., Scott, J., Stewart, R., Menicucci, D., 1987. A new simplified version of the Perez diffuse irradiance model for tilted surfaces. Sol. Energy 39 (3), 221-232.

Perez, R., Ineichen, P., Seals, R., Michalsky, J., Stewart, R., 1990. Modelling daylight availability and irradiance components from direct and global irradiance. Sol. Energy 44 (5), 271-289.

Perspective Pilot. $<$ http://www.colorpilot.com/perspective.html $>$.

PTLens, $<$ http://epaperpress.com/ptlens/>.

Quaschning, V., Hanitsch, R., 1996. Numerical simulation of currentvoltage characteristic of photovoltaic systems with shaded solar cells. Sol. Energy 56 (6), 513-520.

Quaschning, V., Hanitsch, R., 1998. Irradiance calculation on shaded surfaces. Sol. Energy 62 (5), 369-375.

Radiance. $<$ http://radsite.lbl.gov/radiance/HOME.html $>$.

Ramalingam, S., Sturm, P., Lodha, S.K., 2010. Generic self-calibration of central cameras. Comput. Vis. Image Underst. 114 (2), 210-219.

Reindl, D.T., Beckmann, W.A., Duffie, J.A., 1990a. Diffuse fraction correlations. Sol. Energy 45 (1), 1-7.

Reindl, D.T., Beckmann, W.A., Duffie, J.A., 1990b. Evaluation of hourly tilted surface radiation models. Sol. Energy 45 (1), 9-17.

Ricolfe-Viala, C., Sánchez-Salmerón, A., 2010. Robust metric calibration of non-linear camera lens distortion. Pattern Recogn. 43 (4), 1688-1699.
Robinson, D., Stone, A., 2004. Solar radiation modelling in the urban context. Sol. Energy 77 (3), 295-309.

Shading II. <http://ayezioro.technion.ac.il/>.

ShadowFX. <http://www.shadowfx.co.uk $>$.

Skiba, M., Faller, F.R., Eikmeier, B., Ziolek, A., Unger, H., 2000. Skiameter shading analysis. In: Proceedings of the 16th EC PV Solar Energy Conference, Glasgow, pp. 2402-2105.

Solar Tool. $<$ http://www.squ1.com $>$.

Solar-2. $<$ http://www.aud.ucla.edu/energy-design-tools $>$.

Sombrero 3.01. $<$ http://nesa1.uni-siegen.de/>.

Sun_Chart Solar Design Software. <http://www.srv.net/opt/ sunchrt.html>.

Suncast. $<$ http://www.ies4d.com>.

Sundi. $<$ http://emsolar.ee.tu-berlin.de/simulation/sundi.html $>$.

Tomori, T. Otani, K., Sakuta, K., Kurokawa, K., 2000. On-site BIPV array shading evaluation tool using stereo-fisheye photographs. In: Proceedings of the 28th IEEE Photovoltaic Specialists Conference, Ancorage, AK, pp. 1599-1602.

Torres, J.L., De Blas, M., Garcia, A., 2006. New equations for the calculation of the horizon brightness irradiance in the model of Perez. Sol. Energy 80 (7), 746-750.

Torres, J.L., Garcia, A., De Blas, M., De Francisco, A., 2008. Calculation of the horizon brightness irradiance in the model of Perez using the unit-sphere method. Renew. Energy 33 (1), 149-154.

Torres, J.L., De Blas, M., Garcia, A., De Francisco, A., 2010. Comparative study of various models in estimating hourly diffuse solar irradiance. Renew. Energy 35 (6), 1325-1332.

TRNSYS. $<$ http://www.trnsys.com/ $>$.

Van den Heuvel, F., 1998. 3D reconstruction from a single image using geometric constraints. Photogramm. Remote Sens. 53, 354 368.

Wang, J., Shi, F., Zhang, J., Liu, Y., 2008. A new calibration model of camera distortion. Pattern Recogn. 41 (2), 607-615.

Woyte, A., 1997. Charakterisierung von Abschattenden Objekten und ihr Einfluss auf den Energieertrag von Photovoltaik-Anlagen. Universität Hannover, Fachbereich Elektrotechnik and Institut für Solarenergieforschung, Hannover.

Wu, L., Cao, X., Foroosh, H., 2010. Camera calibration and geo-location estimation from two shadow trajectories. Comput. Vis. Image Underst. 114 (8), 915-927.

Zhao, Z., Liu, Y., 2010. Applications of projected circle centers in camera calibration. Mach. Vis. Appl. 21 (3), 301-307. 